UNIVERSIDADE ESTADUAL PAULISTA “JÚLIO DE MESQUITA FILHO” FACULDADE DE CIÊNCIAS AGRONÔMICAS CAMPUS DE BOTUCATU

\title{
DESENVOLVIMENTO DE UM SISTEMA COMPUTACIONAL PARA TRATAMENTO DE DADOS METEOROLÓGICOS NO SETOR DE AGROENERGIA
}

\section{DANIELA LUCHESI}

Dissertação apresentada à Faculdade de Ciências Agronômicas da UNESP - Campus de Botucatu, para obtenção do título de Mestre em Agronomia Energia na Agricultura.

BOTUCATU - SP

Agosto - 2009 
UNIVERSIDADE ESTADUAL PAULISTA “JÚLIO DE MESQUITA FILHO” FACULDADE DE CIÊNCIAS AGRONÔMICAS CAMPUS DE BOTUCATU

\title{
DESENVOLVIMENTO DE UM SISTEMA COMPUTACIONAL PARA TRATAMENTO DE DADOS METEOROLÓGICOS NO SETOR DE AGROENERGIA
}

\author{
DANIELA LUCHESI
}

Orientador: Prof ${ }^{0}$ Dr. Saulo Philipe Sebastião Guerra

Dissertação apresentada à Faculdade de Ciências Agronômicas da UNESP - Campus de Botucatu, para obtenção do título de Mestre em Agronomia - Energia na Agricultura.

BOTUCATU - SP

Agosto - 2009 
FICHA CATALOGRÁFICA ELABORADA PELA SEÇÃO TÉCNICA DE AQUISIÇÃO E TRATAMENTO DA INFORMAÇÃO - SERVIÇO TÉCNICO DE BIBLIOTECA E DOCUMENTAÇÃO - UNESP - FCA - LAGEADO - BOTUCATU (SP)

Desenvolvimento de um sistema computacional para tratamento de dados meteorológicos no setor de agroenergia / Daniela Luchesi. - Botucatu : [s.n.], 2009. vi, 48 f. : il. color., gráfs., tabs.

Dissertação (Mestrado) - Universidade Estadual Paulista, Faculdade de Ciências Agronômicas, Botucatu, 2009 Orientador: Saulo Philipe Sebastião Guerra Inclui bibliografia.

1. Informática agrícola. 2. Agricultura e energia. 3. Dados - Tratamento. I. Guerra, Saulo Philipe Sebastião. II. Universidade Estadual Paulista "Júlio de Mesquita Filho" (Campus de Botucatu). Faculdade de Ciências Agronômicas. III. Título. 


\section{UNIVERSIDADE ESTADUAL PAULISTA “JÚLIO DE MESQUITA FILHO” FACULDADE DE CIÊNCIAS AGRONÔMICAS}

CAMPUS DE BOTUCATU

\section{CERTIFICADO DE APROVAÇÃO}

TÍTUlO: "DESENVOLVIMENTO DE UM SISTEMA COMPUTACIONAL PARA TRATAMENTO DE DADOS METEOROLÓGICOS NO SETOR DE AGROENERGIA"

\section{ALUNA: DANIELA LUCHESI}

ORIENTADOR: PROF. DR. SAULO PHILIPE SEBASTIÃO GUERRA

Aprovado pela Comissão Examinadora
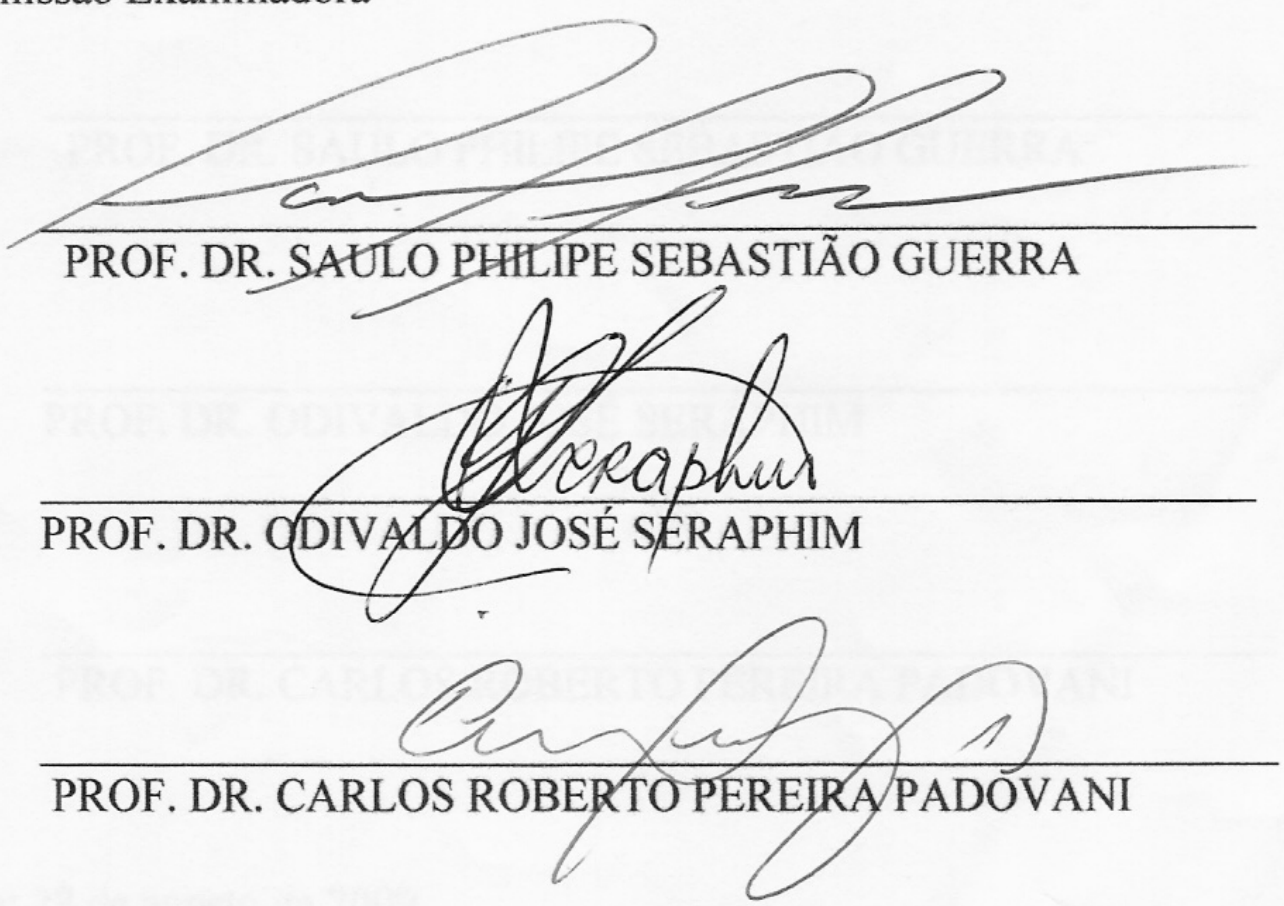

Data da Realização: 28 de agosto de 2009. 
“A maior recompensa do nosso trabalho não é o que nos pagam por ele,

mas aquilo em que ele nos transforma."

(John Ruskin)

\section{DEDICO}

Aos meus pais, Ruth e Antonino e

as minhas irmãs, Fabiane e Luciana.

OFEREÇO

Ao meu avô paterno, Waldemar Luchesi.

(in memorian) 


\section{AGRADECIMENTOS}

À Deus Pai, nosso Senhor e Criador, sempre presente em minha caminhada.

À Faculdade de Ciências Agronômicas (FCA - UNESP), campus de Botucatu e ao Prof $f^{\circ}$ Dr. Marco Antonio Martin Biaggioni, coordenador do programa de PósGraduação em Agronomia - Energia na Agricultura, pela oportunidade concedida para a execução da pesquisa.

Aos professores Doutores Saulo Philipe Sebastião Guerra, Odivaldo José Seraphim e Zacarias Xavier de Barros pela orientação precisa, amizade, dedicação, compreensão e paciência em todas as fases do curso, enfim a todos os docentes do Mestrado pelos conhecimentos adquiridos.

As secretárias, aos técnicos e funcionários da Seção de Pós-Graduação da Faculdade de Ciências Agronômicas (FCA - UNESP), pela solicitude e presteza no atendimento.

Aos amigos Carlos Alberto Machado Moreira, Élvio Gilberto da Silva, Roque Maitino Neto e Wiliam Carlos Galvão pelo incentivo, apoio, carinho, compreensão e respeito.

Enfim, a todas as pessoas, instituições e empresas que, de uma forma ou de outra, contribuíram para a realização deste trabalho de pesquisa.

Obrigada a todos que me ajudaram a chegar até aqui. Vocês permanecerão para sempre em minha lembrança. 


\section{SUMÁRIO}

Página

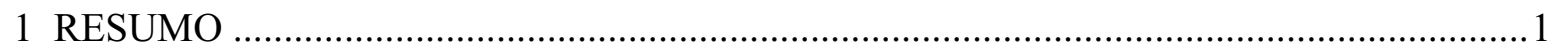

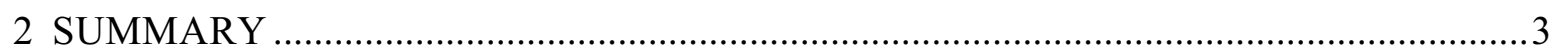

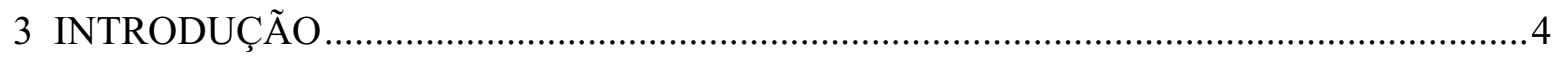

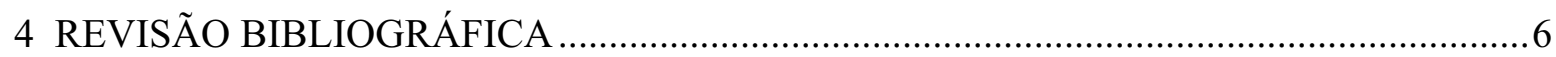

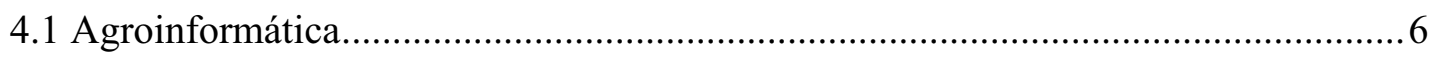

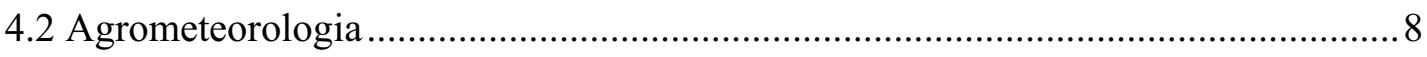

4.3 Sistemas computacionais e sistemas de informação.................................................. 9

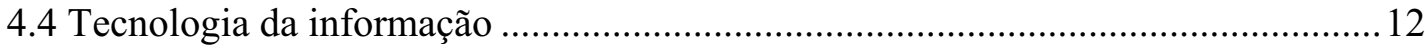

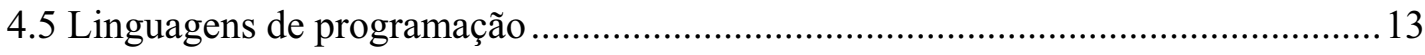

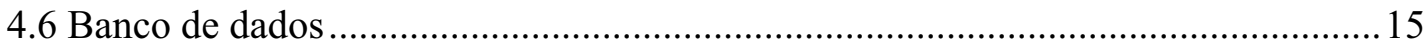

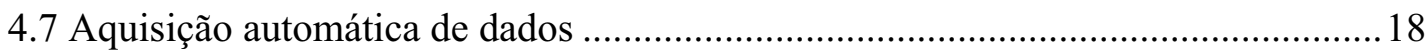

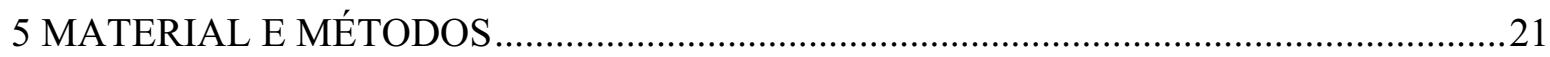

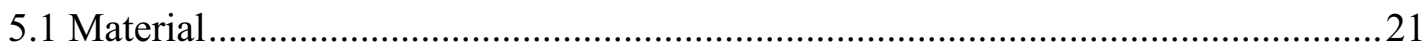

5.1.1 Descrição da área de estudo..................................................................21

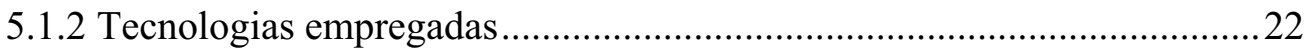

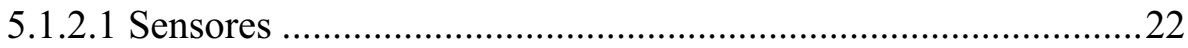

5.1.2.2 Sistema automático de aquisição de dados ................................24

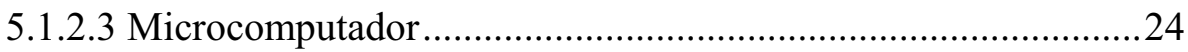

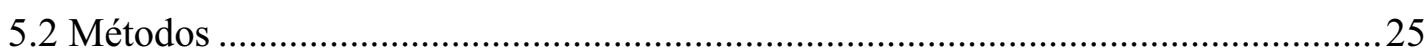

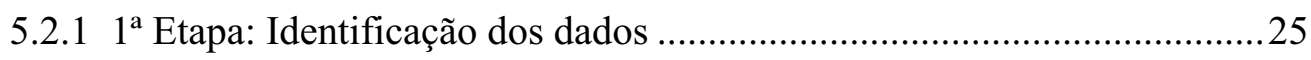

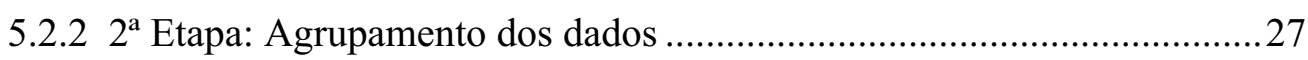

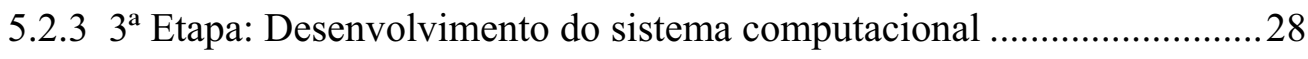

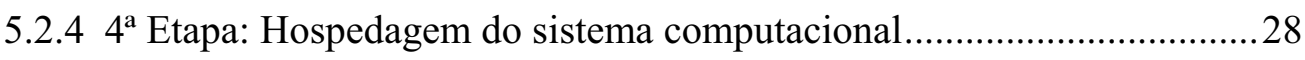

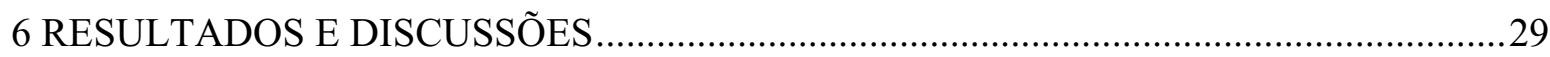

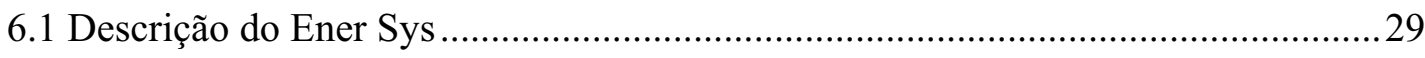

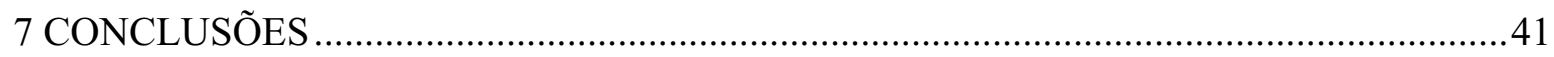

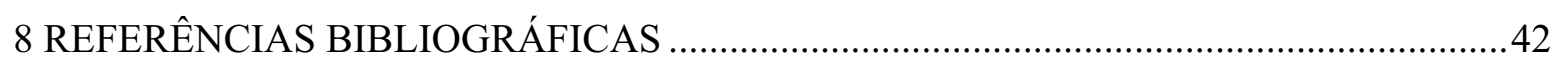




\section{LISTA DE FIGURAS}

Figura

Página

Figura 1 - Componentes genéricos de um sistema. Adaptado de OLIVEIRA, (2002).

Figura 2 - Vista NEAR e da instalação do sistema híbrido eólico fotovoltaico. 1 - Painel fotovoltaico do sistema; 2 - Aerogerador do sistema; $\mathrm{N}$ = Norte geográfico do local. Adaptado de SIQUEIRA, (2005).

Figura 3 - Torre instrumentada com os equipamentos de aquisição de dados instalados. 1 Anemômetro; 2 - Piranômetro; 3 - Termo higrômetro; 4 - Datalogger CR23-X. Adaptado de

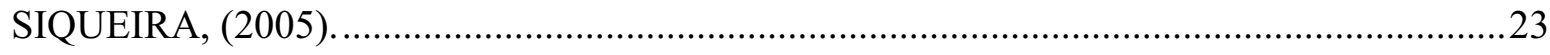

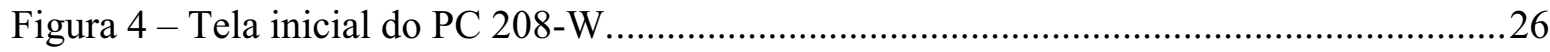

Figura 5 - Arquivo texto gerado pelo sistema automático de aquisição de dados....................26

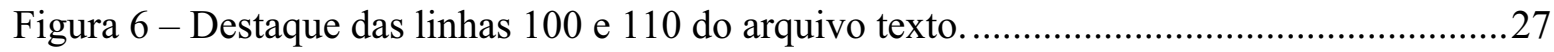

Figura 7 - Seqüência de execução do Ener Sys .........................................................................30

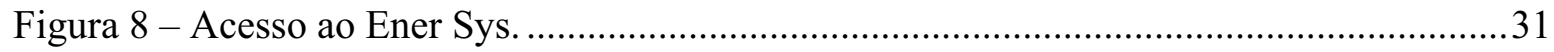

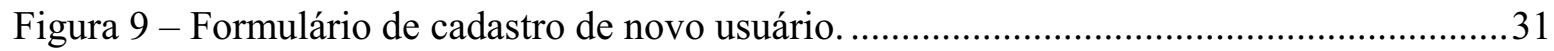

Figura 10 - Apresentação inicial do Ener Sys ao administrador.................................................32

Figura 11 - Apresentação inicial do Ener Sys ao usuário. ...........................................................32

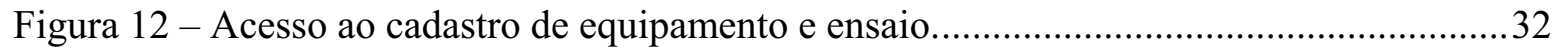

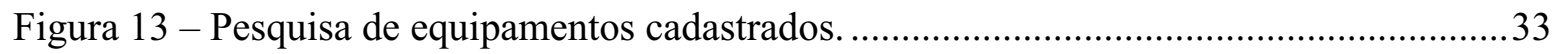

Figura 14 - Informações do equipamento de aquisição de dados. ...........................................33

Figura 15 - Formulário de acesso à edição e exclusão de equipamentos...................................34

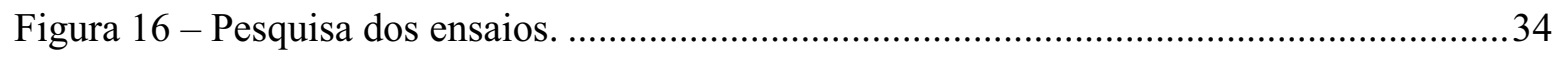

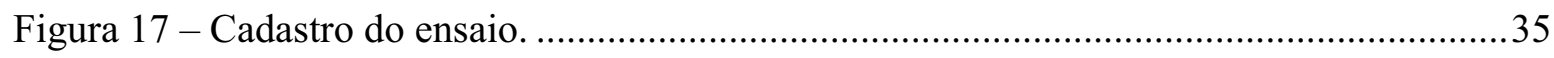

Figura 18 - Formulário de edição e exclusão do ensaio..........................................................35

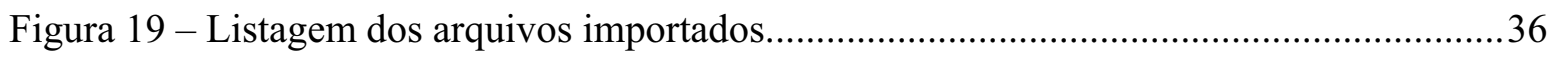

Figura 20 - Inclusão de um arquivo para importação. ..............................................................36

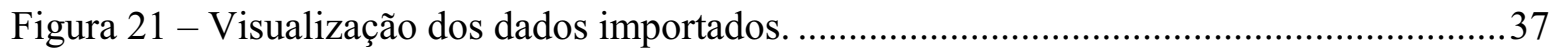

Figura 22 - Formulário de escolha dos dados do relatório........................................................38

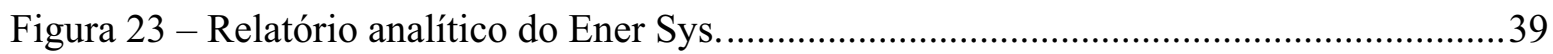




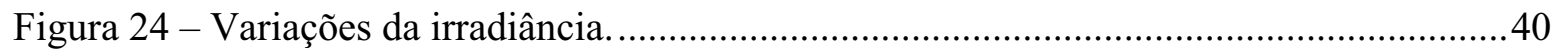

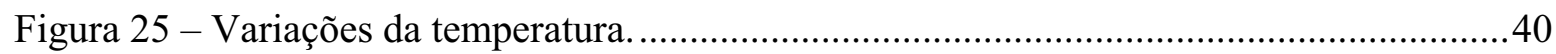

Figura 26 - Variações da umidade relativa. ....................................................................... 41

Figura 27 - Variações da velocidade do vento................................................................... 41

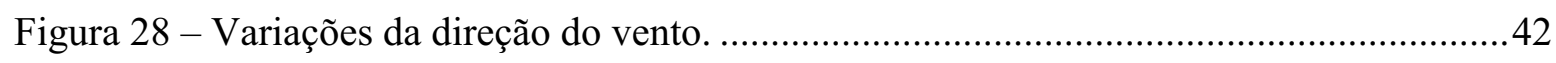

Figura 29 - Variações do índice pluviométrico......................................................................42

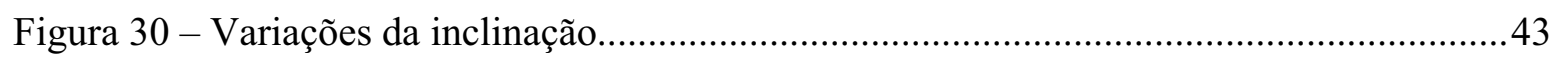

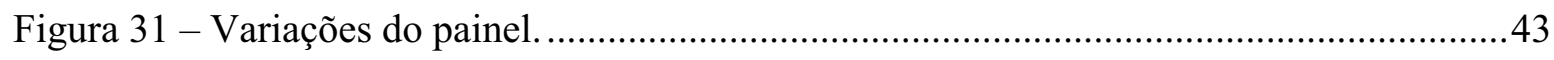




\section{RESUMO}

A agroinformática, termo criado para referenciar a informática aplicada à agricultura, vem ganhando espaço e se organizando nesse novo processo de modernização da agricultura na tentativa de contribuir tanto no aumento da produtividade quanto da qualidade. A informática no ambiente agrícola se encontra presente em diversas propriedades rurais, tanto na área administrativa como na área de gestão proporcionando coordenação nas atividades, uma maior agilidade no fluxo de informações e redução de erros nas operações internas.

Em função da crescente presença da informática na agricultura e da utilização de dispositivos de aquisição automática de dados no campo, a presente pesquisa apresenta o desenvolvimento de um programa computacional, Ener Sys, desenvolvido com o objetivo de transformar dados meteorológicos no setor de agroenergia.

A partir de um dispositivo automático de aquisição de dados (Campbell Scientific modelo CR23X), desenvolveu-se um sistema computacional para melhor classificar e visualizar os dados de uma forma rápida e simples para o profissional envolvido com as alterações meteorológicas da área sob estudo. O sistema proposto utilizou as seguintes tecnologias computacionais: a linguagem de programação Personal Home Page Hypertext Preprocessor e o banco de dados Firebird.

Os resultados obtidos ao término da pesquisa apontam que a abordagem deste trabalho facilitou o acesso a informações armazenadas em grandes massas de dados. $\mathrm{O}$ 
programa computacional desenvolvido, reuniu em uma base unificada, os dados coletados através de um sistema eletrônico de aquisição de dados e facilitou o processamento dos dados proporcionando ganhos na visualização das informações como temperatura $\left({ }^{\circ} \mathrm{C}\right)$, umidade $(\%)$, velocidade do vento $\left(\mathrm{m} . \mathrm{s}^{-2}\right)$, direção do vento (graus), chuva (mm) e irradiância (horizontal e vertical). 
DEVELOPMENT OF A SOFTWARE FOR PROCESSING DATA IN AGROENERGY. Botucatu, 2009, 48 p.

Dissertação (Mestrado em Agronomia/Energia na Agricultura) - Faculdade de Ciências Agronômicas, Universidade Estadual Paulista.

Author: DANIELA LUCHESI

Advisor: SAULO PHILIPE SEBASTIÃO GUERRA

\section{SUMMARY}

The agro-informatics, term used as reference to the informatics applied to the agriculture, it has been gaining space and getting organized on this new process of agriculture modernization to try to contribute both to the productivity increase and quality. The informatics at the agricultural environment can be found in many rural properties both in the administrative area and management area, providing coordination in the activities, a better agility with the information flow and error cutback in the internal operations.

Due to the growing presence of the informatics in the agriculture and the use of automatic data acquisition devices in the field, this study presents a computer program, Ener Sys, developed with the purpose of transform meteorological data in the agro sector.

From an automatic device of data acquisition (Campbell Scientific model CR23X) it was developed a computer system to better classify and visualize the data on a fast and simple way to the professional involved with the study of meteorological variations in this area. The suggested system used the following computer technologies: the Personal Home Page Hypertext Preprocessor programming language and the database Firebird.

The results obtained at the end of the research show that the approach of this study made easier the access to the information stored in large amounts of data. The computer program developed, put together in one base, the data collected through an electronic system of data acquisition and made easy the data processing providing a gain on the visualization of information such as temperature $\left({ }^{\circ} \mathrm{C}\right)$, humidity $(\%)$, wind speed $\left(\mathrm{m} . \mathrm{s}^{-2}\right)$, wind direction (degrees), rain (mm) and irradiance (horizontal and vertical).

Keywords: computer system, data treatment, agro-informatics, agro-energy. 


\section{INTRODUÇÃO}

$\mathrm{O}$ agronegócio brasileiro encontra-se em um momento que exige e propicia a geração, difusão e utilização de modernas técnicas de administração da propriedade agrícola. Somente assim, o produtor terá instrumentos efetivos para auxiliá-lo no planejamento, implementação, direção e controle das atividades a serem executadas.

Atualmente, o agronegócio reveste-se da mesma complexidade e dinâmica dos demais setores da economia, requerendo do produtor uma nova visão da gestão de seus negócios, principalmente pela necessidade de abandonar a posição tradicional de fazendeiro para assumir o papel de empresário rural.

Com a globalização de mercados, o sucesso de uma empresa, principalmente no agronegócio, depende cada vez mais da inter-relação entre fornecedores, produtores de matéria prima, processadores e distribuidores $\mathrm{O}$ conceito de agronegócio representa, portanto o enfoque moderno que considera todas as empresas que produzem, processam, e distribuem produtos agropecuários.

É necessário introduzir novas tecnologias de suporte administrativo, rompendo com práticas tradicionais e possibilitando o surgimento de novas abordagens gerenciais.

A informática pode auxiliar para facilitar a gerência dos novos sistemas produtivos que surgirão e para agilizar o processo decisório, permitindo um melhor planejamento das atividades agropecuárias, em busca da otimização da aplicação dos conceitos embutidos nesses sistemas. A tecnologia da informação vem se difundindo no meio rural, nos últimos anos, e verifica-se que ela pode contribuir positivamente nos aspectos econômicos e ambientais. 
Os profissionais que atuam hoje no agronegócio têm importância elevada nesse contexto. Entretanto, existe uma demanda crescente e urgente por profissionais que possam atuar em toda a cadeia industrial, permitindo o aumento da eficiência do mercado de insumos agropecuários, produção agropecuária, processamento industrial e distribuição.

Dessa forma qualquer empresa ou organização necessita de mão-de-obra capacitada para atuar nas relações entre empresas, equacionar soluções, pensar estrategicamente, introduzir modificações, atuar preventivamente, transferir e gerar conhecimentos, com uma visão ampla de toda a cadeia de produção.

Assim, a formação dos profissionais nesta área envolve capacitação em informática, economia, mercado, finanças, administração, contabilidade e pesquisa operacional, além de aplicações práticas modernas de gerenciamento e controle do agronegócio.

O enfoque do agronegócio é essencial para retratar as profundas transformações verificadas na agricultura, nas últimas décadas, período no qual o setor primário deixou de ser um mero provedor de alimentos in natura e consumidor de seus próprios produtos, para ser uma atividade integrada aos setores industriais e de serviços.

A informática pode facilitar a gerência dos novos sistemas produtivos que surgirão e para dinamizar o processo decisório, permitindo um melhor planejamento das atividades agropecuárias, em busca da otimização da aplicação dos conceitos embutidos nesses sistemas. A tecnologia da informação vem se difundindo no meio rural nos últimos anos e verifica-se que ela pode contribuir positivamente nos aspectos econômicos e ambientais. Nesse contexto, a agroinformática - termo criado para referenciar a informática aplicada à agricultura - vem ganhando espaço e se organizando.

Em função da crescente presença da informática na agricultura e da utilização de dispositivos de aquisição automática de dados no campo, o presente trabalho apresenta um programa computacional desenvolvido com o intuito de transformar dados agro meteorológicos, lidos a partir de sensores, em informações úteis e de fácil visualização para o profissional envolvido com o estudo das alterações meteorológicas da área sob estudo. 


\section{REVISÃO BIBLIOGRÁFICA}

\subsection{Agroinformática}

A agroinformática, termo criado para referenciar a informática aplicada à agricultura, vem ganhando espaço e se organizando (MEIRA et al., 1996).

A utilização da informática vem destacando-se como uma ferramenta indispensável na gerência dos processos administrativos, em que tomadas de decisão, rápidas e seguras, representam condição básica para o sucesso das atividades (Machado et al., 2002).

Segundo Jesus et al. (1996), a informatização na propriedade agrícola apresenta três estratégias básicas: a opção de longo prazo, na qual o programa atende a todos os requisitos, mas o custo é alto, tanto de desenvolvimento, como de manutenção; a opção de curto prazo e menor custo, na qual os pacotes mais utilizados são planilhas eletrônicas, gerenciadores de banco de dados e editores de texto, que têm aplicação limitada e a opção intermediária, na qual corre-se o risco de aceitar que sejam controlados aspectos não relevantes em detrimento de outros mais relacionados com os objetivos e estratégias da organização.

De acordo com Machado et al. (2002), o rápido desenvolvimento da informática, associado às sensíveis reduções de custos de seus produtos e serviços, aumentou a 
possibilidade dos computadores ajudarem o empreendedor rural na organização, por meio do armazenamento e processamento das informações.

A quantidade de programas de computador desenvolvidos para setor de agronegócios tem aumentado. A oferta de programas computacionais voltados a negócios agropecuários sofreu acréscimo de 54\% em 1997 e 17\% em 1999 (BARBOSA et al., 2000).

Até a década de 70 , pouco se falava de informática na agropecuária fora dos centros de pesquisa. No início dos anos 80, a informática avançou no setor agropecuário brasileiro, deixando de ser exclusividade dos centros de pesquisa e ensino, em conseqüência da expansão da micro-informática e da redução dos preços dos produtos (MENDONÇA, 1995).

No período de introdução da informática nos empreendimentos rurais, a maior barreira ao crescimento dessa tecnologia estava na falta de programas e soluções específicas dirigidas ao setor (MACHADO et al., 2002).

Com o advento da informática no campo, houve preocupação com relação ao impacto social que sua utilização em larga escala poderia causar no trabalhador rural. Estudos realizados por Burrell et al. (2004) demonstram que o impacto social pode ser minimizado com a adoção de treinamento e capacitação especificamente voltados ao perfil do homem do campo.

Tsvi et al. (2009) desenvolveram sistema de apoio a decisão baseado na rede mundial de computadores para auxiliar agricultores a otimizar e monitorar o uso de fungicidas à base de cobre em videiras orgânicas da Europa.

Segundo Zazueta et al. (2002), a tecnologia presentemente utilizada nas áreas rurais inclui redes, recursos de telecomunicação, bases de dados, multimídia, sistemas de informações geográficas e aparelhos do tipo assistente pessoal digital, entre outros. Estudos conduzidos pelos autores confirmaram que a mobilidade dos assistentes pessoais digitais em lavouras distantes proporcionou aumento da confiabilidade dos dados coletados nestas lavouras. 


\subsection{Agrometeorologia}

Segundo Pereira et al. (2002), a agricultura é uma atividade econômica que depende fortemente das informações do tempo e do clima, que vêm ganhando cada vez mais espaço na tomada de decisões operacionais das atividades agrícolas cotidianas.

De acordo com Sugimoto (2005), no Brasil, o serviço de previsão do tempo tem o agricultor como o maior usuário deste serviço. Para o produtor do campo, são fundamentais os dados climáticos históricos, que lhe permitem decidir qual cultura plantar numa região e em que época do ano, assim como são importantes as previsões mais imediatas para a tomada de decisões.

As condições meteorológicas constituem um dos principais fatores que condicionam o desenvolvimento e a produção agrícola. Em conseqüência, a informação agrometeorológica é muito importante no planejamento das atividades agrícolas, pois situações agrometeorológicas adversas podem acarretar graves impactos sociais e a enormes prejuízos econômicos, muitas vezes difíceis de serem quantificados (AYOADE, 1986).

Mozny et al. (2009) concluíram trabalho sobre o impacto das mudanças climáticas no rendimento e qualidade de uma cultura de lúpulo. Seus experimentos sugeriram que esta cultura é particularmente vulnerável até mesmo a elevações pequenas na temperatura local, com prejuizo de seu crescimento e de sua qualidade. A concentração do cultivo em uma pequena região torna-o mais vulnerável ao clima do que se a produção fosse espalhada por áreas com diversidades maiores de temperaturas.

Mohammed e Tarpley (2008) conduziram pesquisa na Costa do Golfo dos Estados Unidos e detectaram que temperaturas noturnas próximas de $32^{\circ} \mathrm{C}$ afetavam os teores de clorofila, os teores de nitrogênio nas folhas, a porcentagem de geminação do pólen e a fertilidade em culturas de arroz. Com base nestes dados e conclusões, foram aplicadas substâncias que reduziram os efeitos da alta temperatura noturna.

Almeida et al., (2008) elaboraram trabalho comparativo entre os dados obtidos por estação meteorológica convencional e por estação meteorológica automática. As análises estatísticas comparativas entre os dados da primeira estação e os dados coletado na segunda, mostraram índices estatísticos de concordância, exatidão e precisão elevados e, conseqüentemente, concordância entre si. As pequenas discrepâncias encontradas estão 
associadas à precisão instrumental e/ou à freqüência de amostragens nos cálculos das médias diárias.

\subsection{Sistemas computacionais e sistemas de informação}

Segundo Stair (2002), sistema é um conjunto de elementos ou componentes que interagem para atingir um objetivo. Segundo O'Brien (2004), sistema é um conjunto de métodos, procedimentos ou técnicas unificados por interação controlada para formar um todo organizado.

Os componentes de um sistema são apresentados na Figura 1. por Oliveira (2002) .As partes integrantes de um sistema são apresentadas como sendo os objetivos, tanto os do usuário quanto os do próprio sistema; as entradas, que constituem as fontes de recursos e informações para o sistema; o processo de transformação das entradas; as saídas do sistema, que correspondem aos resultados esperados e que devem estar em sintonia como os objetivos anteriormente traçados; os controles e avaliações do sistema, que servem para aferir os resultados e a retroalimentação, que constitui introdução de uma saída do sistema como uma entrada para o mesmo, com a intenção de reduzir as eventuais discrepâncias ao mínimo e criar condições para que o sistema se torne auto-regulador. Um sistema computacional é caracterizado como a configuração completa de um computador incluindo os periféricos (parte física) e o sistema operacional (parte lógica).

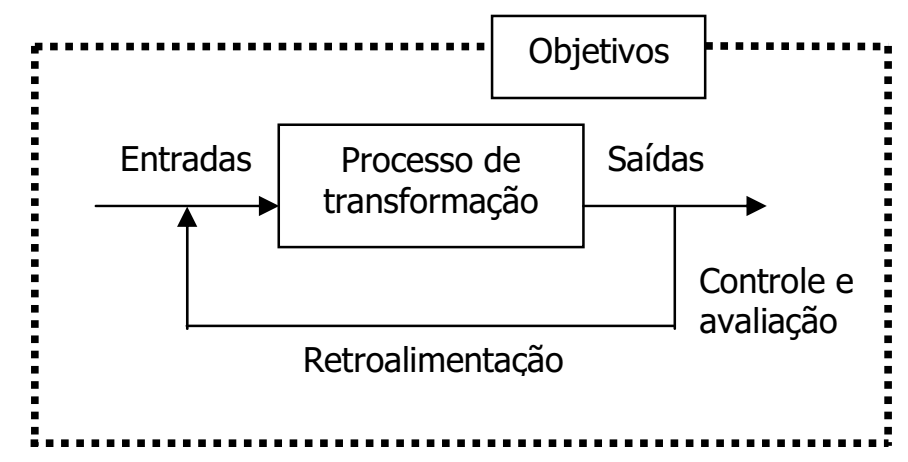

Figura 1 - Componentes genéricos de um sistema. 
Laudon e Laudon (1999) definem a parte física do computador como sendo dispositivos usados para o trabalho de entrada, processamento e saída em um sistema de informação e a parte lógica como instruções pré-programadas que coordenam o trabalho dos componentes de do computador para desempenhar os processos exigidos pelos sistemas de informação.

De acordo com Oliveira (2002), a informação é o produto da análise dos dados existentes na empresa, devidamente registrados, classificados, organizados, relacionados e interpretados em um determinado contexto, para transmitir conhecimento e permitir a tomada de decisão de forma aperfeiçoada.

Do ponto de vista da utilização gerencial da informação, afirma Meirelles (1994), que na viabilização técnica e econômica do uso da informática no tratamento da informação, pesa de forma decisiva o valor desta. Até meados da década de 1970, os custos dos Sistemas de Informação ainda eram superiores aos benefícios para a grande maioria das aplicações.

Em âmbito organizacional, de acordo com Oliveira (2002), as informações podem ser classificadas como informações seletivas, que é técnica que leva ao público, à comunidade ao governo e à concorrência, informações institucionais sobre a empresa, geralmente através de páginas na rede mundial de computadores, folders, anúncios, entre outros; informações obrigatórias ou legais, caracterizadas pela sua obrigatoriedade, periodicidade e são impostas por lei e pela convenção (notas fiscais, recibos, balanços financeiros e declarações) e informações complementares, que são caracterizadas por serem informações que precedem a outras, servindo como apêndice ou complemento. Podem ser descrições, comentários, narrações, explicações, anexos e gráficos.

Segundo Laudon e Laudon (1999), sistemas de informação são componentes relacionados entre si atuando conjuntamente para coletar, processar e prover informações aos sistemas e/ou processos de decisão, coordenando, controlando, analisando e visualizando processos internos às organizações.

Norton (1996), diz que os sistemas de informação existem a mais tempo que os computadores, telefones e aparelhos de fax. O conjunto de regras e procedimentos direcionado ao fornecimento preciso e oportuno de informações aos entes de uma organização constitui um Sistema de Informação. Sob sua ótica, qualquer empresa ou organização que 
tenha uma estrutura administrativa também possui um sistema de informações gerenciais, formal ou não, documentado ou não.

Os sistemas de informação têm sido igualmente importantes para a agricultura. Seu objetivo principal é o de auxiliar na tomada de decisões importantes dentro do processo produtivo e na definição de políticas para o setor agrícola (FREITAS; 1996).

Para Tung (1992), o advento do computador proporcionou significativos avanços nos sistemas de informação. Esses sistemas são classificados em três categorias: sistemas de processamento de transações (cuja função consiste em manter os dados da empresa atualizados e seus registros em dia, pela emissão de documentos apropriados), sistemas de informações gerenciais (para o qual são fornecidos os dados passados, presentes e projetados os objetivos da organização, visando à tomada de decisão) e sistemas de apoio a decisões, que fornecem instrumentos úteis à tomada de decisão. Este sistema utiliza programas variados, pois cada problema, em função de suas características, requer uma solução específica

Atualmente, existe uma quantidade considerável de programas voltados para o campo. Contudo, por melhor que seja o programa, é difícil que o produtor alcance bons resultados sem que haja um preparo da propriedade antes de introduzi-lo (MEIRA et al., 1996).

Meira et al. (1996), afirma que a ferramenta não pode vir antes da administração. É preciso primeiro profissionalizar o gerenciamento, depois comprar o computador. Esta etapa preliminar pode ser chamada de estruturação e precede a etapa de automação - a efetiva adoção da tecnologia de informática.

Os sistemas automatizados poderão ser utilizados pelos próprios produtores, para organizar e profissionalizar a gerência de suas propriedades. A tendência é de que a demanda por aplicativos agropecuários aumente substancialmente. Mas se estes aplicativos forem produzidos através do processo convencional de desenvolvimento de programa computacional, ou seja, de maneira artesanal, essa demanda não poderá ser atendida (MEIRA et al., 1996).

A agricultura brasileira passa por uma fase em que é preciso uma grande reformulação das políticas agrárias governamentais e uma profunda modernização dos sistemas produtivos, com relação tanto às práticas agropecuárias aplicadas quanto à forma de gerenciamento das atividades rurais. O interesse do produtor rural é a rentabilidade de sua 
atividade, de tal maneira que possa obter o máximo retorno econômico de suas atividades. (CASTRO et al ,2002).

Para Machado et al. (2002), a utilização da informática destaca-se como uma ferramenta indispensável na gerência dos processos administrativos, em que tomadas de decisão, rápidas e seguras, representam condição básica para o sucesso das atividades.

Assim sendo, sistemas de computador estão sendo desenvolvidos com o objetivo de ajudar produtores e profissionais agrícolas na tomada de decisões (LOPES, 1997).

Contudo, a adoção da informática nos empreendimentos rurais implica em mudanças na gestão da produção e na organização do trabalho (ZAMBALDE et al., 2008). É indiscutível a importância do uso do computador como mecanismo auxiliar no processo decisório, mas as informações obtidas precisam ser acompanhadas de treinamento para seu aperfeiçoamento dentro da realidade de cada produtor. Dados consistentes devem ser inseridos no sistema a fim de gerar informações úteis à tomada de decisões (SOUKI e ZAMBALDE, 1999).

\subsection{Tecnologia da informação}

A presença da informática é cada vez mais importante e imprescindível em praticamente todos os campos da atividade humana. Pouco se faz, atualmente, sem a utilização, por menor que seja, de algum recurso computacional (ZULLO JUNIOR, 1995).

Figueira e Zambalde (2003), afirmam que a tecnologia da informação (TI), que surgiu como um centro de dados para processar transações, manter o registro dos estoques e emitir a folha de pagamento, passou a ser aplicada em funções de controle, assim como funções executivas que exigem um julgamento para a tomada de decisão.

Segundo Stephenson e Anderson (1997), até o final da de 1970, o uso dos recursos da tecnologia da informação foi limitado a poucos departamentos especializados em universidades, grandes companhias e o governo. Entre o final da década de 1970 e meados da década de 1980, o microprocessador ofereceu uma capacidade de computação, embora limitada, a um grande número de organizações e indivíduos. As informações me tempo real, o suporte, a tomada de decisão e o planejamento de programas e projetos passaram a fazer parte das aplicações operacionais. No final dos anos 1980, os microcomputadores tornaram-se mais 
poderosos, mais integrados e mais portáteis. A comunicação por computador emergiu como uma prática tecnológica para interligar os profissionais em uma base global. Do início dos anos 90 em diante, equipamentos computacionais interconectados transformaram-se em componentes indispensáveis para as operações no mundo.

Segundo Campos Filho (1994), tecnologia da informação é o conjunto de dispositivos e programas computacionais que desempenham uma ou mais tarefas de processamento de informações, fazendo parte do sistema de informação das organizações, que inclui coletar, transmitir, estocar, recuperar, manipular e exibir dados.

Oliveira (2002), define tecnologia da informação como sendo um complexo que inclui computadores, redes de comunicação públicas e privadas, subprodutos da interpenetração das tecnologias de computação e comunicação, além de todos os produtos e serviços usualmente abrigados sob os rótulos de automação de escritório de escritórios, rede digital de serviços integrados e automação comercial.

A tecnologia da informação começou a ser aplicada com sucesso nas propriedades rurais com a automatização das tarefas de contabilidade, de controle de recursos humanos e de controle de estoques e de maquinário (MEIRA et al., 1996).

O uso da tecnologia da informação pelas organizações, em geral, é de vital importância para alcançar uma posição competitiva confortável no mercado global. Embora com atraso, as organizações do agronegócio também estão entrando nesse mundo, numa velocidade e nível de adoção diferente das empresas que não fazem parte do agronegócio (CASTRO NETO et al., 2002). Os aplicativos agropecuários são um exemplo de como a tecnologia da informação pode contribuir para a melhoria da qualidade e o aumento da produtividade na agricultura.

\subsection{Linguagens de programação}

Uma das principais metas das linguagens de programação é permitir que programadores tenham uma maior produtividade, permitindo expressar suas intenções mais facilmente do que quando comparado com a linguagem que um computador entende nativamente (código de máquina). Assim, as linguagens de programação são projetadas para adotar uma sintaxe de nível mais alto, que pode ser mais facilmente entendida por 
programadores humanos. As linguagens de programação são ferramentas importantes para que programadores e engenheiros de programa computacional possam escrever programas mais organizados e com maior rapidez (ALVES, 2005).

Para Meirelles (1994), linguagem de programação é um conjunto de convenções e regras que especificam como transmitir informações entre pessoas e máquinas. De forma simplificada, ela é composta pelo vocabulário (conjunto de símbolos) e pela gramática (conjunto de regras).

Sebesta (2003), diz que diversas linguagens de programação foram criadas para os mais variados domínios de aplicação. Exemplos destes domínios são aplicações científicas, aplicações comerciais, inteligência artificial, programação de sistemas e linguagens de propósitos especiais.

Niederauer (2008), destaca que a linguagem de programação Personal Home Page Hypertext Preprocessor possui características que facilitam a importação e visualização de dados, fato que levou à sua utilização no desenvolvimento do sistema computacional.

Segundo Converse et al. (2004), o Personal Home Page Hypertext Preprocessor é uma linguagem de programação de código aberto, apropriada para criação de aplicativos Web, executado pelo servidor e compatível com a maioria dos servidores, notadamente o Apache. O produto foi originalmente chamado Personal Home Page Tools mas passou a se chamar PHP: Hypertext Preprocessor. Atualmente a linguagem se encontra em sua quinta versão, chamada Personal Home Page Hypertext Preprocessor5.

Soares (2007) relata que trata-se de uma poderosa linguagem de programação de código aberto, mundialmente utilizada. Em termos gerais, a linguagem não possui funcionalidades voltadas a configuração visual de tela, eventos de periféricos de entrada ou qualquer outra particularidade relacionada a aparência da página. Na verdade, a maioria das funcionalidades do produto é invisível ao usuário final.

De acordo com Welling e Thompson (2003), alguns dos principais concorrentes do Personal Home Page Hypertext Preprocessor5 são Active Server Pages, da Microsoft, ColdFusion, da Macromedia e o Java Server Pages, da Sun. Em comparação a estes produtos, a linguagem possui algumas características que o destacam, como o alto desempenho, interfaces com vários sistemas de banco de dados diferentes, bibliotecas pré- 
definidas para várias funcionalidades, facilidade no aprendizado, portabilidade e disponibilidade do código-fonte.

Ainda segundo Converse et al. (2004), outra característica que torna o produto vantajoso em relação a outros é sua velocidade, especialmente quando utilizado em conjunto com o servidor Apache.

O Apache Server é um software livre, o que significa que qualquer um pode estudar ou alterar seu código-fonte, além de poder utilizá-lo gratuitamente. É graças a essa característica que o software foi (e continua sendo) melhorado ao passar dos anos. Graças ao trabalho muitas vezes voluntário de vários desenvolvedores, o Apache continua sendo o servidor Web mais usado no mundo.

Soares (2002), diz que a linguagem foi criada originalmente por Rasmus Lerdorf, passando a atender um grande número de programadores assim que foi disponibilizada gratuitamente na rede mundial de computadores. Ainda segundo este autor, o Personal Home Page Hypertext Preprocessor permite rápida execução de seus aplicativos, mesmo os mais complexos, sem que seus usuários experimentem queda de desempenho.

Niederauer (2008) destaca funcionalidades da linguagem que auxiliam o programador a fornecer ao usuário facilidades na manipulação de documentos em formato pdf, envio de e-mails e conexões com diversos tipos de banco de dados (incluindo Firebird).

\subsection{Banco de dados}

Para Date (2000), um banco de dados é uma coleção de dados utilizada pelos sistemas de aplicação de uma determinada organização. Um banco de dados, principalmente os que suportam vários usuários, precisa ser capaz de gerenciar múltiplas visões dos dados.

Machado e Abreu (2002), definem banco de dados como uma coleção de fatos registrados que refletem o estado de certos aspectos de interesse do mundo real. A todo momento, o conteúdo do banco de dados representa uma visão instantânea do estão do mundo real. Cada mudança em algum item do bando de dados reflete uma mudança ocorrida na realidade que se está representando.

Velloso (2003) relata que a filosofia moderna de tratamento de informação é a organização em banco de dados. 
Segundo Alves (2005), para se ter um banco de dados, são necessários três ingredientes principais: uma fonte de informação, a partir da qual os dados são derivados; uma interação com o mundo real e um público (grupo de usuários) que demonstra interesse nos dados contidos no banco.

Date (2000) compara banco de dados ao equivalente eletrônico de um armário de arquivamento, em outras palavras, é um sistema computadorizado de armazenamento de registros. Ainda segundo o mesmo autor, arquivos computadorizados são chamados com freqüência de banco de dados. Por sua vez, uma tabela é composta de linhas e colunas, onde as linhas representam os registros do arquivo, e as colunas os campos desses registros.

Marcon (2002) assinala que, com a popularização da Internet, a utilização de bancos de dados vem aumentando dentro das empresas. Com o aumento de usuários, a informação precisa ser localizada cada vez mais rapidamente. No entanto, tal informação pode estar localizada em partes dispersas do mundo, o que torna os bancos de dados a melhor solução para organizar esta grande massa de dados.

Segundo Alves (2005), se um banco de dados é um conjunto de dados relacionados, um sistema de gerenciamento de banco de dados (SGBD) é uma coleção de ferramentas e programas que permitem aos usuários a criação e manutenção do próprio banco de dados. Por meio de uma interface, o SGBD disponibiliza uma interface para que os seus clientes possam incluir, alterar ou consultar dados.

Ainda segundo Date (2000), é possível manipular as informações contidas na base de dados através das operações de adição de arquivos novos no banco de dados, inserção de novos dados nos arquivos existentes, recuperação e eliminação de dados nos arquivos existentes, bem como a renovação permanente de arquivos existentes (vazios ou não) do banco de dados.

As informações em questão podem ser qualquer coisa que tenha significado para o indivíduo ou a organização a que o sistema deve servir, em outras palavras, tudo o que seja necessário para auxiliar no processo geral de tomada de decisões de negócios desse indivíduo ou dessa organização (DATE, 2000).

Para Silberschat e Kort (1999), a ciência da computação desenvolveu um conceito de sistema para aplicar tais necessidades de armazenamento: sistemas de banco de 
dados. Trata-se de conjuntos de dados associados a conjuntos de programas para acesso a esses dados. O conjunto dos dados é comumente chamado de banco de dados.

De acordo com Date (2000), as vantagens de um sistema de bancos de dados sobre os métodos tradicionais baseados em papel são: densidade (não há necessidade de arquivos de papel, possivelmente volumosos); velocidade (a máquina pode obter e atualizar dados com rapidez muito maior que o ser humano); menor trabalho monótono (grande parte do tédio de manter arquivos à mão é eliminada. As tarefas mecânicas são sempre feitas com melhor qualidade por máquinas); atualidade (informações precisas e atualizadas estão disponíveis a qualquer momento para consulta).

Machado e Abreu (2002) separam a descrição da informação em um banco de dados em três níveis. O primeiro deles, chamado modelo conceitual, representa a realidade do problema do ambiente, constituindo-se em uma visão global dos principais dados e relacionamentos, independente das restrições de implementação. $\mathrm{O}$ modelo conceitual, segundo os autores, é a primeira etapa do projeto de um sistema de aplicação em banco de dados. O segundo nível é o modelo lógico, que descreve as estruturas que estarão contidas no banco de dados. O terceiro nível, chamado modelo físico, descreve as estruturas físicas de armazenamento de dados, tais como tamanho de campos, índices, nomes, entre outros.

Elmasri e Navathe (2005) destacam que nos últimos anos, os avanços tecnológicos geraram aplicações inovadoras dos sistemas de banco de dados. Os bancos de dados multimídia podem armazenar figuras, videoclipes e mensagens sonoras. Os sistemas de informações geográficas são capazes de analisar mapas, dados do tempo e imagens de satélite. Por fim, os sistemas de processamento analítico on-line são utilizados em muitas empresas para extrair e analisar as informações úteis dos bancos de dados para tomada de decisões.

Para armazenamento das informações processadas pelo sistema computacional proposto neste trabalho foi utilizado o sistema gerenciador de banco de dados Firebird.

Segundo Cantu (2005), o Firebird é baseado no código do InterBase da Borland. Com a abertura de seu código fonte na versão 6.0 (em 25 de Julho de 2000), alguns programadores, em associação, assumiram o projeto de identificar e corrigir inúmeros erros da versão original. Surge assim o Firebird, que se tornou um banco com características próprias, obtendo uma aceitação imediata no círculo de programadores, a primeira versão 1.0. Ainda 
compatível com sua versão origem, o produto encontra-se na versão 2. Lançada recentemente, esta nova versão apresenta muitas inovações. O produto se mostrou bastante seguro, suportando sistemas com dezenas de usuários simultâneos e bases de dados acima de $2 \mathrm{~GB}$ de tamanho. Há suporte gratuito na Internet através de vários sites.

\subsection{Aquisição automática de dados}

Com a utilização de equipamentos que coletam dados na forma digital, há a necessidades de ferramentas específicas que facilitem o processamento dessa informação, para depois interpretá-la de forma adequada, devido à grande quantidade de dados obtidos neste tipo de equipamentos; sendo que a ferramenta empregada no manuseio dos dados pode facilitar ou dificultar o seu processamento na obtenção do resultado requerido. (CUNHA, 2001).

Para Ajimastro Jr. e Paz (1998) é necessário introduzir novas tecnologias de suporte administrativo, rompendo com as práticas tradicionais e possibilitando o surgimento de novas abordagens gerenciais.

Saraiva et al. (1998) ponderam que é necessário processar os dados para, inicialmente quantificar a variabilidade existente e avaliar sua relevância.

Para Braga (2008), aquisição de dados significa obter informação de algum processo físico através da medição de suas grandezas, que serão digitalizadas de forma a permitir a aplicação de algum tipo de processamento matemático que irá torná-lo compatível, para fim de comparação, com grandezas padronizadas. Após isso será analisado e armazenado. Qualquer sistema de aquisição irá apresentar alguns blocos, ou funções, básicas: sensores, condicionamento de sinal, conversão analógico-digital e processamento. Os sensores são responsáveis por converter variações dos fenômenos físicos como pressão, temperatura, nível de iluminação, tensão, corrente e potência em sinais elétricos.

Segundo Silveira (2005), alguns tipos de sensores também são conhecidos como transdutores, embora transdutores sejam responsáveis pela conversão de um tipo de energia em outro tipo que pode não ser elétrica. Nestes casos o sensor será formado por um transdutor mais algum dispositivo que transforme a nova forma de energia em um sinal elétrico. A escolha dos sensores é parte fundamental da definição de um sistema de aquisição 
de dados porque será diretamente responsável pela sua eficiência e precisão. A aquisição de dados é uma operação básica a todo o processo de desenvolvimento científico, industrial ou mesmo médico. Suas aplicações vão desde as mais simples como medir uma tensão até as altamente complexas e de alta confiabilidade como o controle de uma planta industrial. $\mathrm{O}$ processo básico é o mesmo, o que irá mudar é a forma e a complexidade dos elementos utilizados. A escolha do equipamento e programa computacional a serem usados deverá ser baseada nas grandezas a serem medidas e na precisão desejada.

Segundo Campos (2009), os dados obtidos através de equipamentos eletrônicos como, por exemplo, os sensores, devem ser processados para se transformarem em informações úteis, gerando atividades que justificam a utilização da informática na agricultura: sua capacidade de manipular um grande número de dados e efetuar cálculos com grande rapidez. Nesse contexto a utilização de um microcomputador com um programa computacional específico para aquisição de dados contribui de maneira importante com pesquisadores e produtores.

A aquisição de dados, segundo Garcia et al. (2003), é uma atividade essencial em todo tipo de tecnologia e ciência, tem como um de seus objetivos, apresentar, ao observador, os valores das variáveis ou parâmetros que estão sendo medidos.

Segundo Johnson (1997), a coleta de dados pode ser automatizada sem colocar em xeque a precisão dos dados obtidos. Através da aquisição automática de dados eliminam-se erros gerados pela transcrição de dados, além de aumentar a taxa de leitura das variáveis.

De acordo com Almeida et al. (2008), as estações meteorológicas convencionais em uso no Brasil e no mundo vão, aos poucos, sendo substituídas por estações automáticas, visando não somente ampliar os locais de coletas de dados, especialmente para aqueles inóspitos à observação convencional, mas buscando a melhoria na qualidade dos dados gerados tanto pela maior precisão instrumental quanto pela maior freqüência de obtenção.

Sob a alegação de que a utilização de modelos de culturas em grandes áreas de cultivo para diagnosticar as condições de crescimento ou prever sua produção é prejudicada pela falta de informação espacial suficiente sobre as entradas do modelo, Launay e Guerif (2005) desenvolveram uma forma de espacializar o modelo que assimila informações obtidas a 
partir de imagens de sensoriamento remoto obtidas durante o período de crescimento das plantas.

Concluindo seu trabalho, Launay e Guerif (2005) demonstram que as estimativas feitas com a assimilação de dados provenientes de sensoriamento remoto foram bastante aprimoradas, com a redução do erro médio de $20 \%$ para aproximadamente $10 \%$. Destacam ainda que os fatores-chave que tornaram o método bem sucedido foram a quantidade e o seqüenciamento das imagens, que determinaram o número e o tipo de parâmetros que puderam ser estimados.

A principal função de um dispositivo de aquisição automática de dados é coletar e registrar dados ao longo do tempo ou em relação à dada localização, via sensores e instrumentos externos ou próprios. (SILVEIRA, 2005)

Para Braga (2009), os dispositivos de aquisição automática de dados podem ainda variar entre os de propósito geral - com uma gama considerável de aplicações relacionadas a medições - e aqueles de propósito bem específico, com coletas e medições voltadas a um tipo de ambiente ou aplicação. É comum que os aparelhos de propósito geral sejam programáveis. No entanto, alguns ainda são configurados como máquinas estáticas, com um número limitado de parâmetros.

Conforme observado essa grande tendência tornou-se um fato que iniciou uma grande modificação no meio rural, muitos sistemas de aquisições de dados foram e ainda estão sendo desenvolvidos para cada área específica com a finalidade de obter cada vez mais eficácia na coleta de dados (GUERRA, 2006). 


\section{MATERIAL E MÉTODOS}

\subsection{Material}

\subsubsection{Descrição da área de estudo}

O trabalho foi desenvolvido no Núcleo de Energias Alternativas e Renováveis - NEAR do Laboratório de Energização Rural do Departamento de Engenharia Rural da UNESP, Faculdade de Ciências Agronômicas, Fazenda Experimental Lageado, localizada no município de Botucatu, São Paulo, com localização geográfica definida pelas coordenadas $22^{\circ} 51^{\prime}$ latitude sul (S) e $48^{\circ} 26^{\prime}$ longitude oeste (W) e altitude média de 786 metros acima do nível do mar. A velocidade média mensal do vento a 10 metros de altura é

$3,1 \mathrm{~m} \cdot \mathrm{s}^{-1}$ e a energia solar global média mensal diária é de 4772,13 W.h.m ${ }^{-2}$. A Figura 2 apresenta o NEAR. 


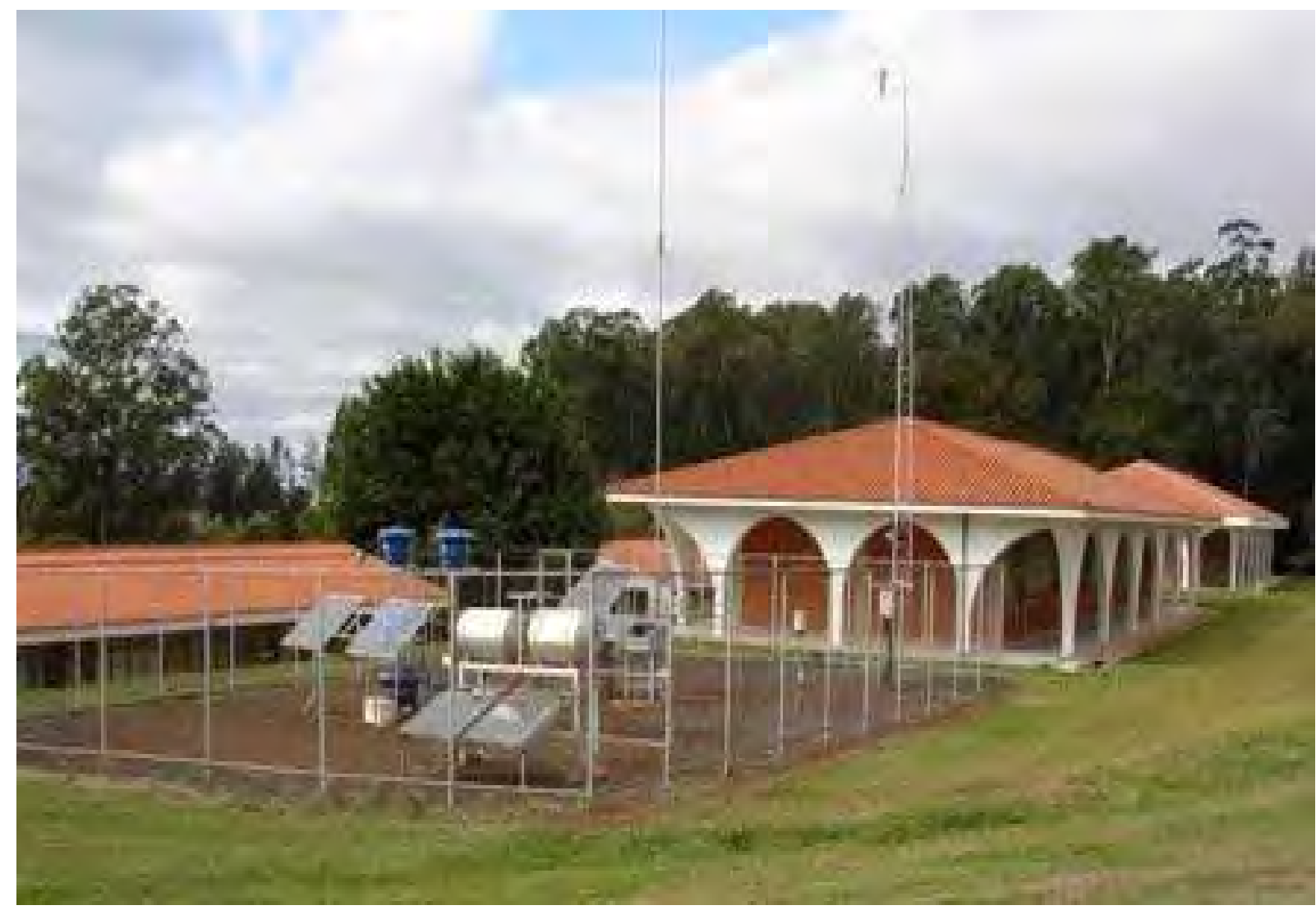

Figura 2 - Vista NEAR

\subsubsection{Tecnologias empregadas}

\subsubsection{Sensores}

Os equipamentos para medição das variáveis meteorológicas e de aquisição de dados do experimento foram instalados em uma torre CAMPBELL UT930, conforme apresentados na Figura 3. A estrutura da torre é confeccionada em alumínio tubular, treliçada e montada sobre uma base triangular. A torre é composta por três seções, com altura total de 10m (SIQUEIRA, 2005). 


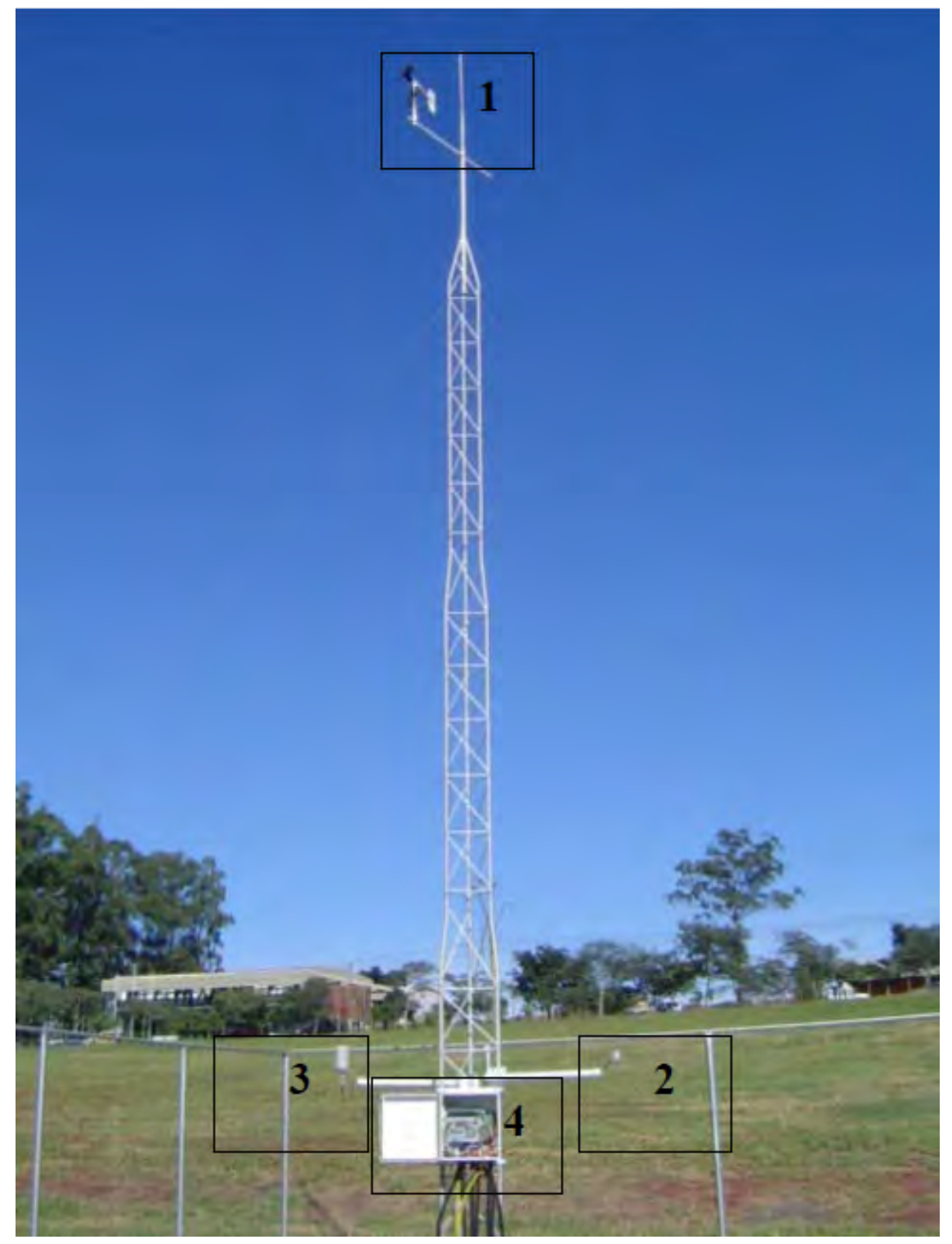

Figura 3 - Torre instrumentada com os equipamentos de aquisição de dados instalados. 1 - Anemômetro; 2 - Piranômetro; 3 - Termo higrômetro; 4 - Datalogger CR23-X.
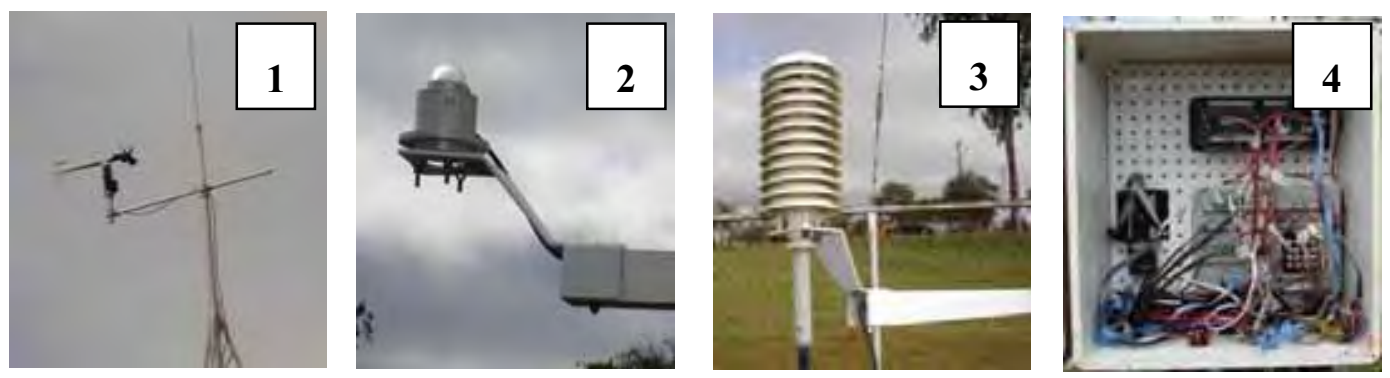


\subsubsection{Sistema automático de aquisição de dados}

Os dados foram coletados automaticamente pelo sistema de aquisição de dados fabricado pela Campbell Scientific, modelo CR23X e armazenados em um microcomputador em tempo real por meio do uso do programa computacional PC 208-W em conexão com a porta serial do microcomputador.

O sistema de aquisição dos dados meteorológicos e elétricos foi programado para efetuar leituras a cada 10 segundos e realizar médias e totalizações dos valores obtidos a cada 5 minutos.

O equipamento efetua medidas de precisão com capacidade de armazenamento e memória para cálculos estatísticos. Possui $512 \mathrm{~Kb}$ de memória para programação, $128 \mathrm{~Kb}$ de memória para cálculos estatísticos e 1Mb de RAM (padrão).

\subsubsection{Microcomputador}

O microcomputador responsável pelo armazenamento e processamento dos dados obtidos através do sistema automático de aquisição de dados foi um microcomputador AMD SEMPRON, modelo LE - 1200, 2.11GHz, 896 de RAM, HD 80Gb, sistema operacional XP Windows Professional 2002, 2 portas USB, CD/DVD. 


\subsection{Métodos}

As rotinas foram desenvolvidas de forma conversacional, com acesso às diversas opções por meio de menus auto-explicativos, o que permite a operação do sistema por pessoas não especializadas em informática, mas apenas treinadas na operação de microcomputadores.

\subsection{1 $1^{a}$ Etapa: Identificação dos dados}

A primeira etapa do processo de desenvolvimento consistiu em identificar, no arquivo gerado pelo programa PC 208-W, os dados das seguintes variáveis: temperatura $\left({ }^{\circ} \mathrm{C}\right)$, umidade $(\%)$, velocidade dos ventos $\left(\mathrm{m} \cdot \mathrm{s}^{-1}\right)$, direção dos ventos (graus), chuva (mm) e irradiância (horizontal e vertical).

O programa computacional PC 208-W, responsável pela coleta dos dados, utiliza uma linguagem específica e diferentes instruções em função do que se quer medir e calcular. Exige como configuração mínima para execução o sistema operacional Windows 98 ou superior.

Através do programa PC 208-W, o usuário executa a programação, o processamento e a comunicação direta com o equipamento responsável pela coleta dos dados.

$\mathrm{Na}$ Figura 4 pode-se observar a tela inicial do programa computacional PC 208-W que coleta os dados no formato texto diretamente do sistema automático de aquisição de dados. 


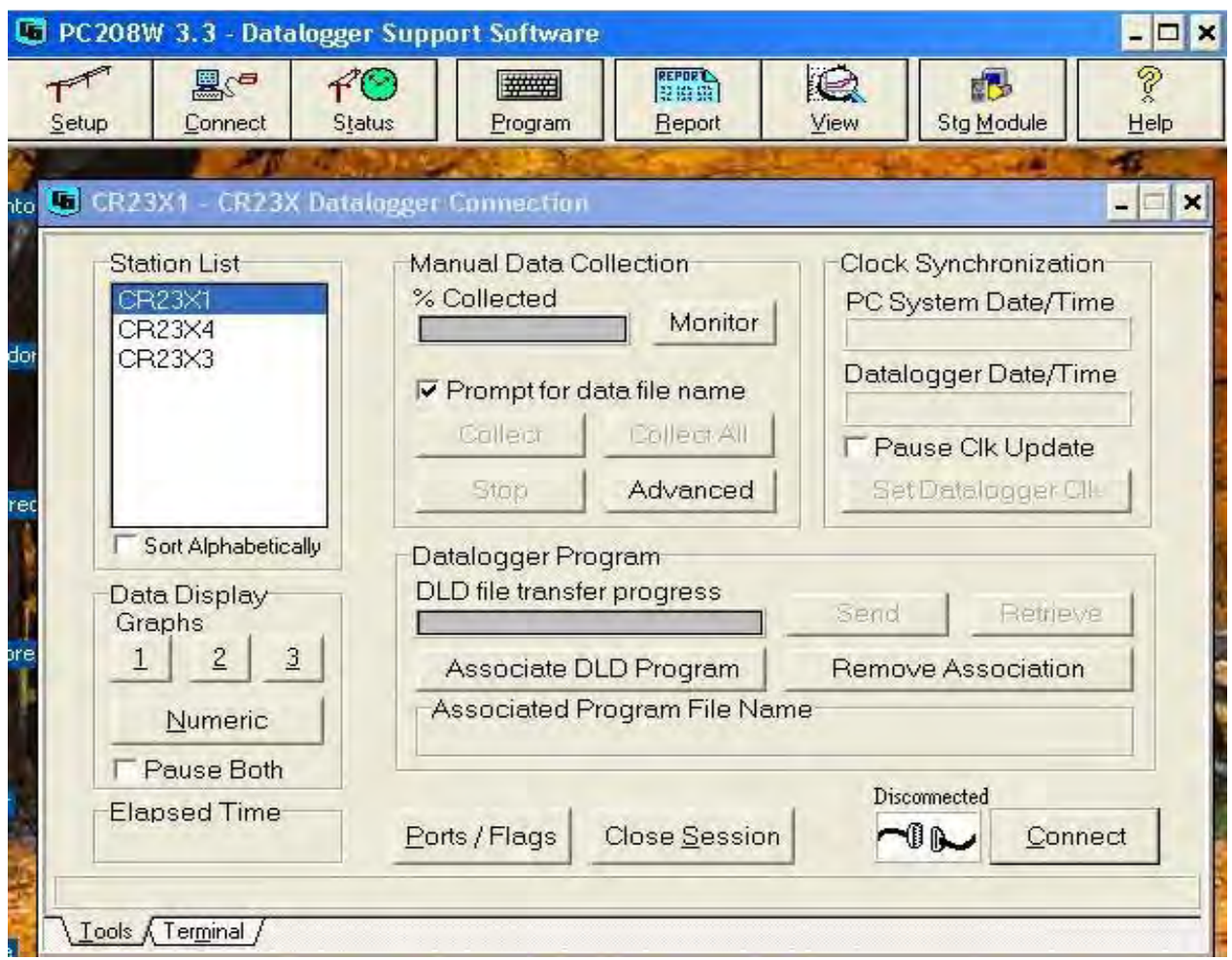

Figura 4 - Tela inicial do PC 208-W.

Os dados coletados diariamente foram armazenados no microcomputador no formato texto. Na Figura 5 pode-se observar o arquivo texto com os dados coletados do sistema automático de aquisição de dados.

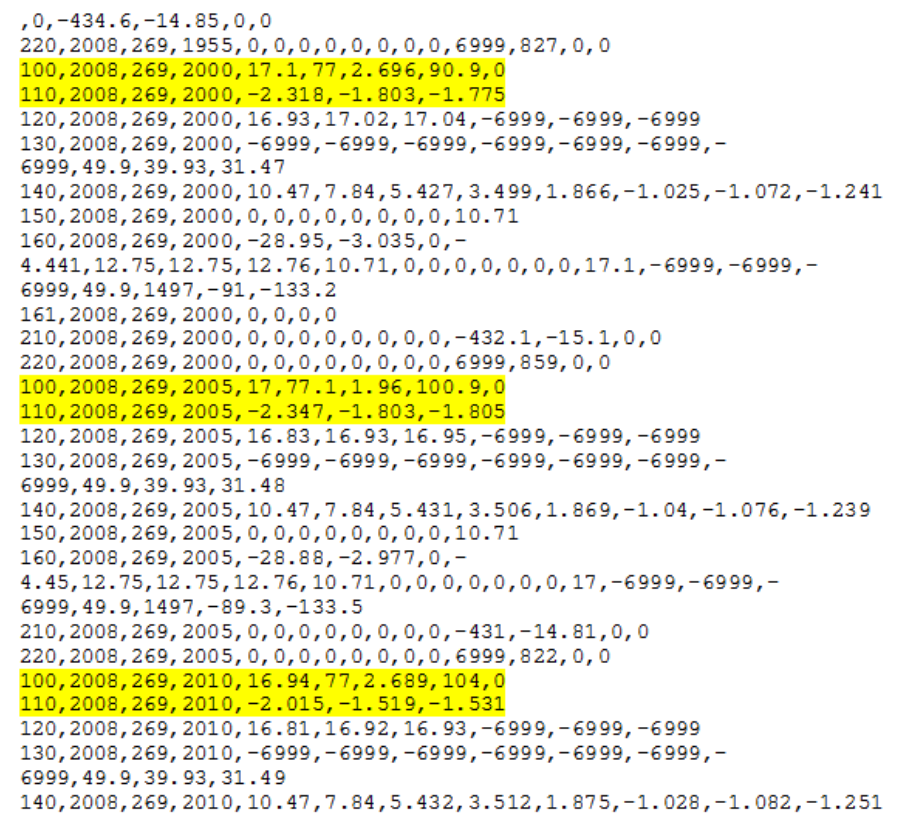

Figura 5 - Arquivo texto gerado pelo sistema automático de aquisição de dados. 
O formato dos dados armazenados é do tipo ASCII, delimitado por vírgulas, tendo o ponto como separador decimal.

As linhas em destaque na Figura 5 representam os dados que serão utilizados pelo sistema computacional desenvolvido para exibição dos dados disponibilizados pelo PC 208-W. A Figura 6 apresenta, em destaque, as linhas 100 e 110 do arquivo no formato texto.

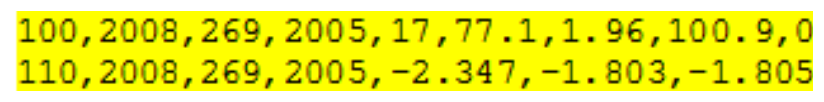

Figura 6 - Destaque das linhas 100 e 110 do arquivo texto.

Na linha 100 encontra-se a representação das seguintes variáveis: a linha, o ano, o dia no formato juliano, hora/minuto, temperatura do $\operatorname{ar}\left({ }^{\circ} \mathrm{C}\right)$, umidade relativa $(\%)$, velocidade do vento $\left(\mathrm{m} \cdot \mathrm{s}^{-1}\right)$, direção do vento (graus), preciptação (mm).

$\mathrm{Na}$ linha 110 podem-se observar variáveis que representam: o número da linha, o ano, o dia no formato juliano, hora, minuto, irradiância (watts. $\mathrm{m}^{-2}$ ) na horizontal (na torre) e inclinados (nos painéis).

\subsubsection{2a Etapa: Agrupamento dos dados}

A segunda etapa do processo de desenvolvimento consistiu no agrupamento num único banco de dados, neste caso o Firebird, das informações armazenadas no período de 2005 a 2008.

A escolha do Firebird como banco de dados usado pelo programa computacional desenvolvido se deu pela sua rapidez na execução das sentenças e pela mínima necessidade de configuração e administração. Além destas características, é capaz de atender igualmente bem à aplicações de um único usuário e aplicações corporativas, onde um simples servidor Firebird pode manipular múltiplas bases de dados independentes. Seu código fonte é totalmente disponível, o que garante transparência ao projeto. 


\subsection{3 $3^{\text {a }}$ Etapa: Desenvolvimento do sistema computacional}

A terceira etapa do projeto consistiu no desenvolvimento do sistema computacional, fazendo uso da linguagem de programação Personal Home Page Hypertext Preprocessor para classificar e visualizar os dados de uma forma mais simplificada ao usuário final.

Esta fase do trabalho utilizou requisitos coletados nas fases de identificação e agrupamento de dados. Após o levantamento de tais requisitos, foi iniciada a fase de projeto do sistema, que produziu representação esquemática do fluxo das operações do sistema e onde foram concebidas as funções do programa. Também durante esta fase foram definidas as estruturas de dados (tabelas e campos) para armazenamento das informações coletadas.

Paralelamente a codificação, foram feitos testes de validação das entradas efetuadas pelo usuário, verificações da efetiva gravação nas tabelas dos dados inseridos e da recuperação destes dados, além ajustes na disposição dos elementos de tela.

\subsection{4 $4^{\text {a }}$ Etapa: Hospedagem do sistema computacional}

A quarta etapa do projeto resultou na hospedagem do sistema computacional desenvolvido em um domínio particular.

Hospedagem de domínios é um serviço que possibilita as pessoas ou empresas com sistemas em tempo real, disponibilizar informações, imagens, vídeos, ou qualquer conteúdo na rede mundial de computadores. Provedores de hospedagem de domínios são tipicamente empresas que fornecem um espaço em seus servidores e conexão à internet, a estes dados aos seus clientes.

Atualmente podemos acessar o sistema através do seguinte endereço eletrônico: www.wftec.fca.unesp.br. 


\section{RESULTADOS E DISCUSSÕES}

A proposta principal deste trabalho baseia-se na construção de uma ferramenta computacional de armazenamento e exibição de variáveis meteorológicas coletadas através de dispositivo de aquisição automática de dados.

Os resultados e discussão apresentados têm o objetivo de demonstrar o funcionamento do programa computacional desenvolvido.

\subsection{Descrição do Ener Sys}

Ener Sys é o nome da ferramenta computacional desenvolvida para facilitar a visualização de informações coletadas por dispositivo de aquisição automática de dados. Por conta da tecnologia utilizada em sua construção, ele pode ser acessado através da rede mundial de computadores, característica que o diferencia do programa atualmente em funcionamento.

Antes da efetiva abordagem da execução e dos passos operacionais do sistema Ener Sys, faz-se necessária a apresentação de visão geral de suas operações através da estrutura exibida na Figura 7. 


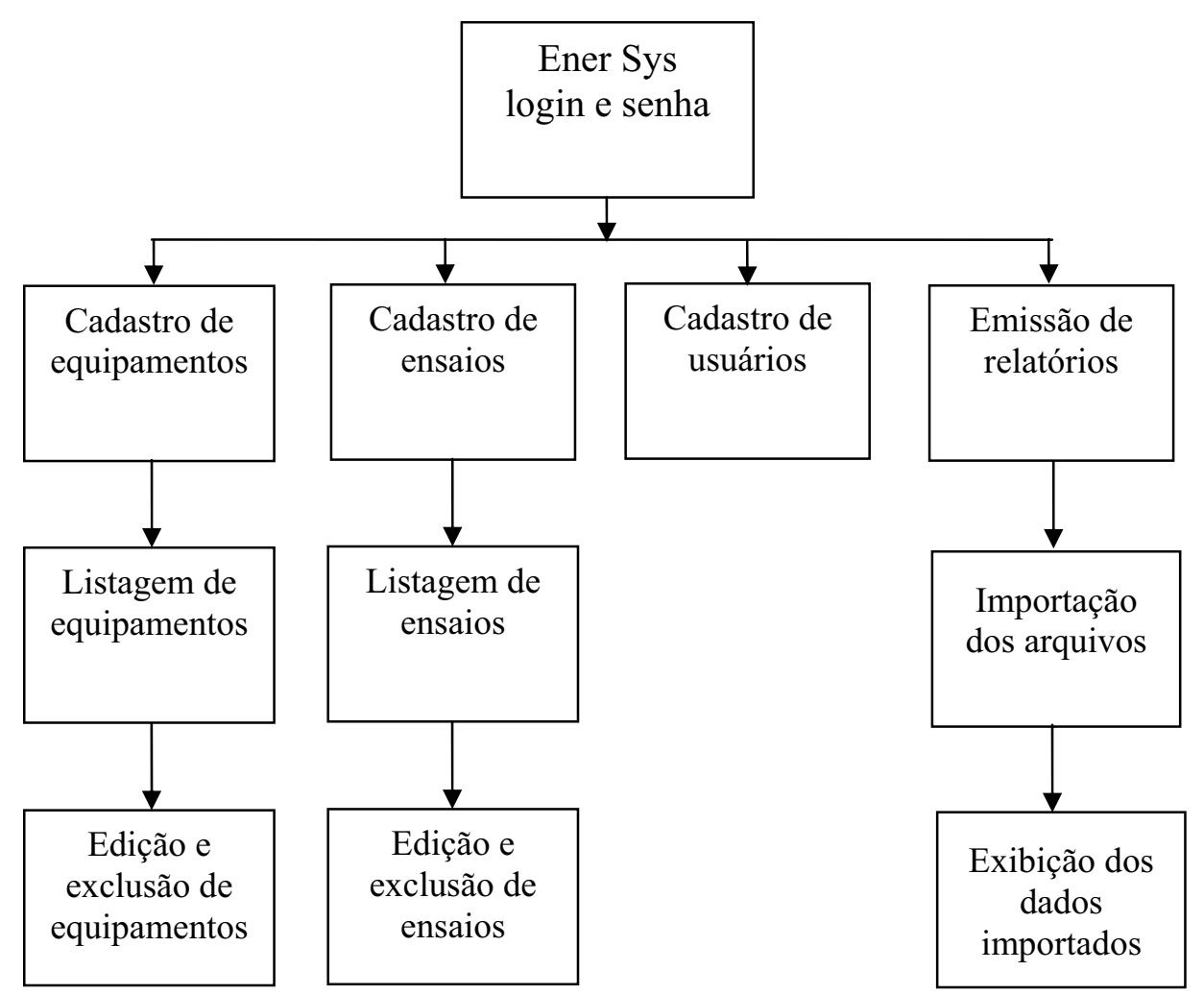

Figura 7 - Seqüência de execução do Ener Sys

A interface gráfica do programa foi desenvolvida de modo a facilitar a entrada dos dados e permitir a visualização dos resultados de maneira rápida e direta. Para a descrição e apresentação que seguem, o sistema foi executado no Internet Explorer 8.

Após a digitação do endereço www.wftec.fca.unesp.br, o usuário é levado à tela de acesso ao Ener Sys, onde são requeridos nome de usuário e senha. A Figura 8 apresenta esta tela. 


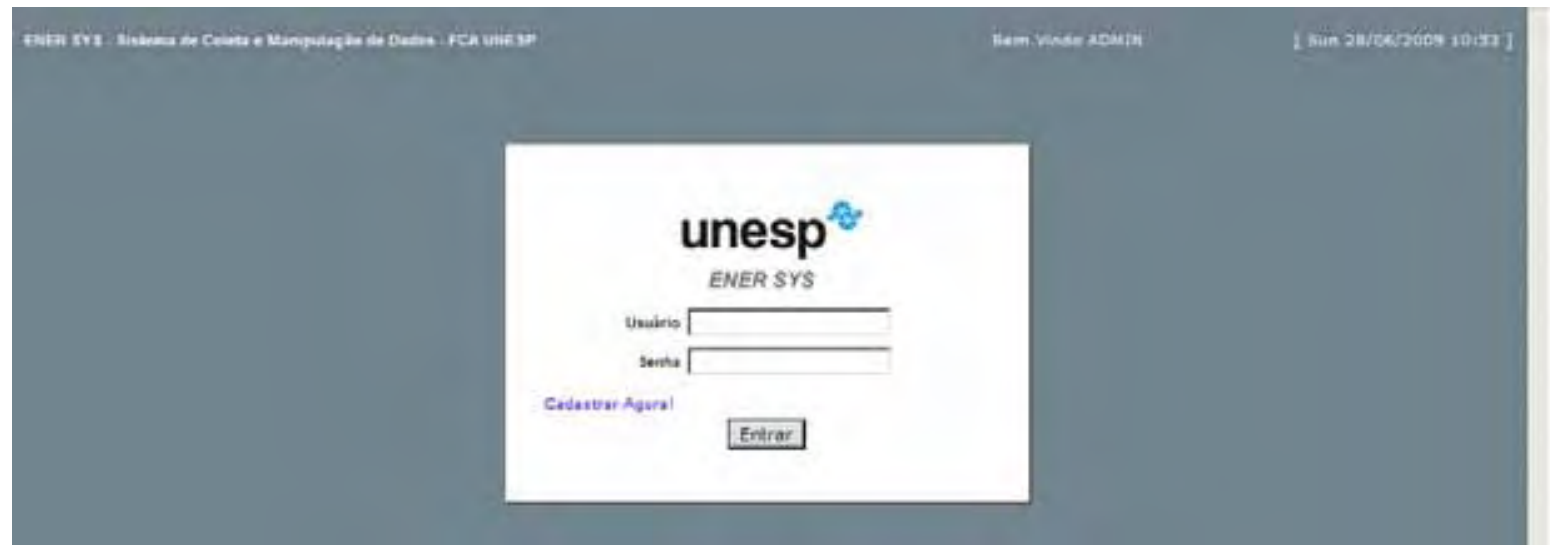

Figura 8 - Acesso ao Ener Sys.

Caso o usuário esteja tentando seu primeiro acesso, a opção Cadastrar Agora o levará à página de formulário exibida na Figura 9. Se o usuário já possuir registro no sistema, após a digitação dos dados de acesso e da seleção do botão Entrar, o nome de usuário e a senha são validados.

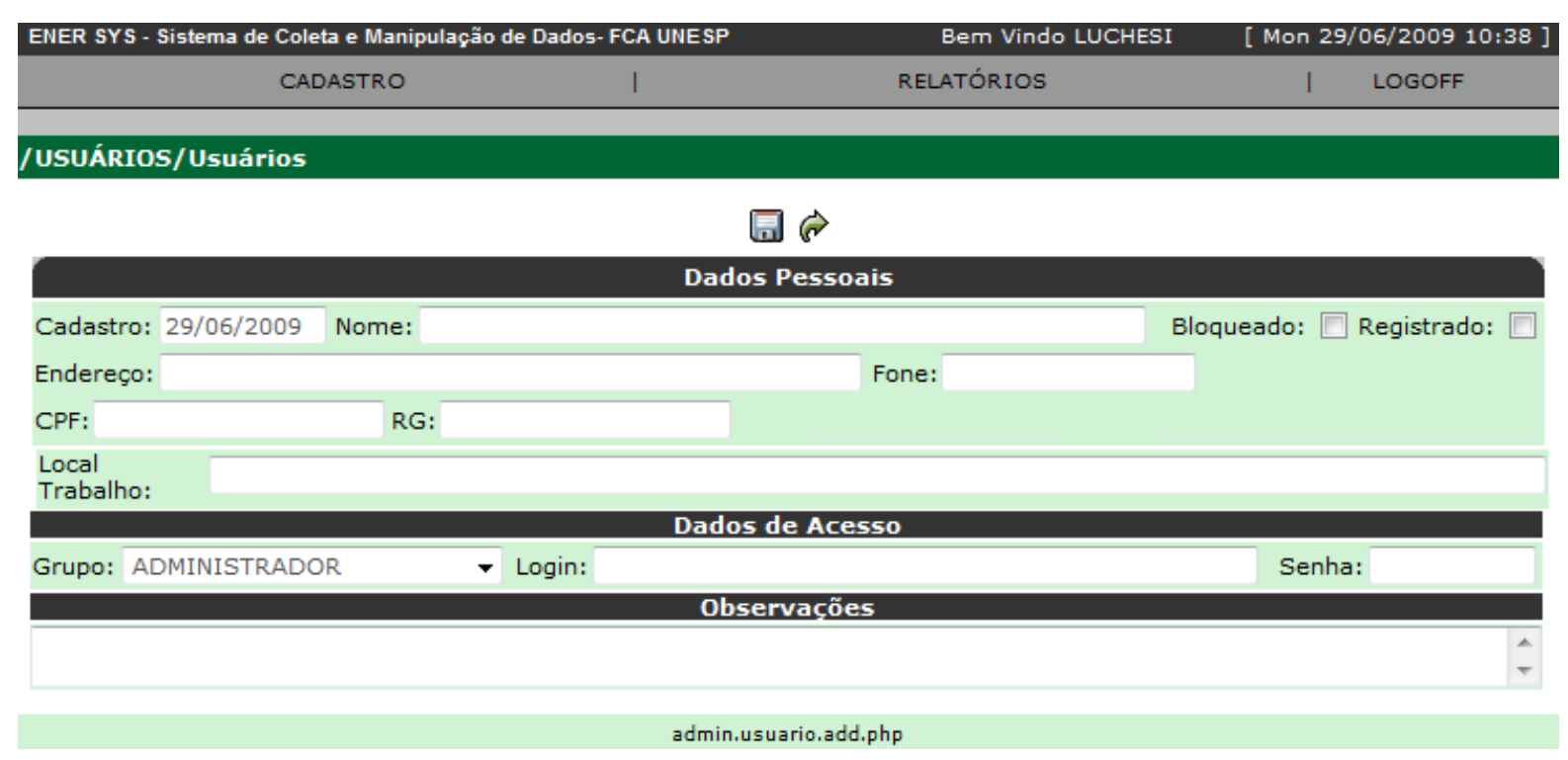

Figura 9 - Formulário de cadastro de novo usuário.

Neste formulário, o usuário deve preencher todos os dados solicitados e, ao final do processo, acionar o ícone para armazenamento dos dados, situado em sua parte superior. 
Após a validação do acesso, caso seja constatado se tratar de usuário com privilégios de Administrador, o sistema permite acesso ao menu principal conforme retratado na Figura 10.

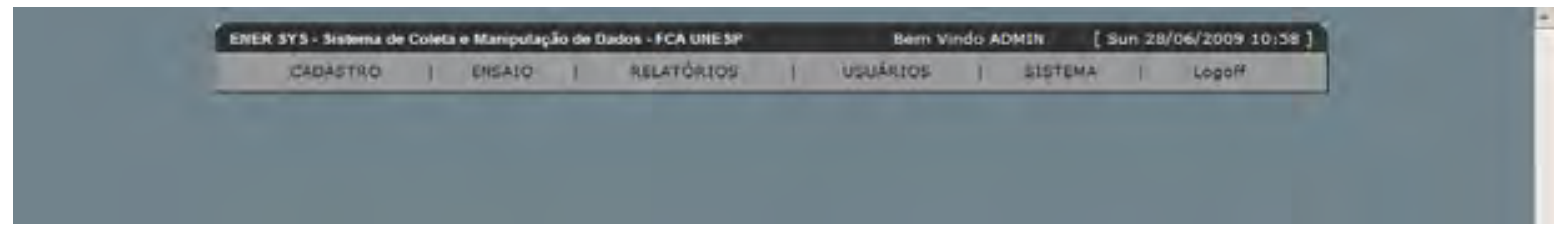

Figura 10 - Apresentação inicial do Ener Sys ao administrador.

Se, no entanto, o usuário não possuir privilégios de administrador do sistema, a página exibida será a mostrada na Figura 11.

Figura 11 - Apresentação inicial do Ener Sys ao usuário.

No contexto do usuário comum (denominação dada ao usuário sem permissões de administrador) é permitido o cadastro do equipamento de aquisição automática de dados e o cadastro do ensaio no sistema. A Figura 12 apresenta o acesso ao cadastro de equipamento e ensaio.

Ao selecionar a opção datalogger, o usuário é levado à página de pesquisa dos equipamentos já cadastrados no sistema. Este formulário contém, além da opção de novo cadastro, a listagem de todos os equipamentos registrados.

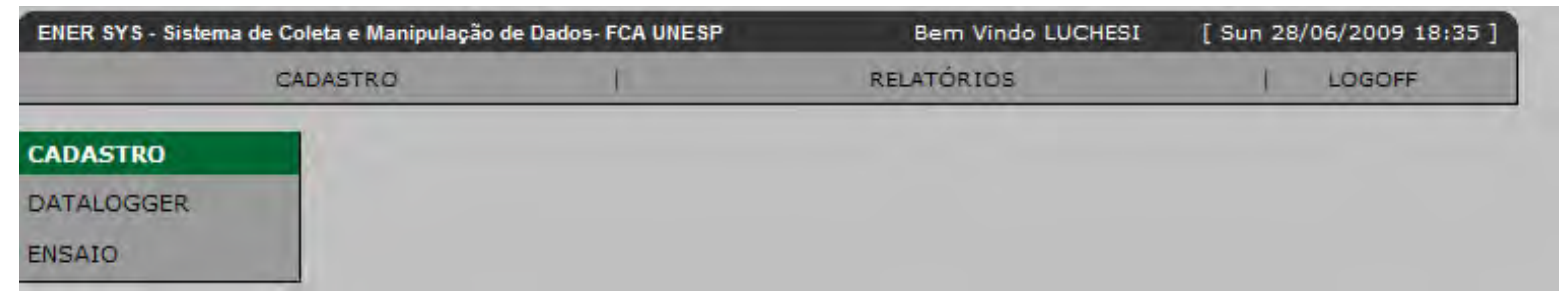

Figura 12 - Acesso ao cadastro de equipamento e ensaio. 
A Figura 13 apresenta formulário contendo resultado da pesquisa de equipamentos de aquisição automática de dados já incluídos.

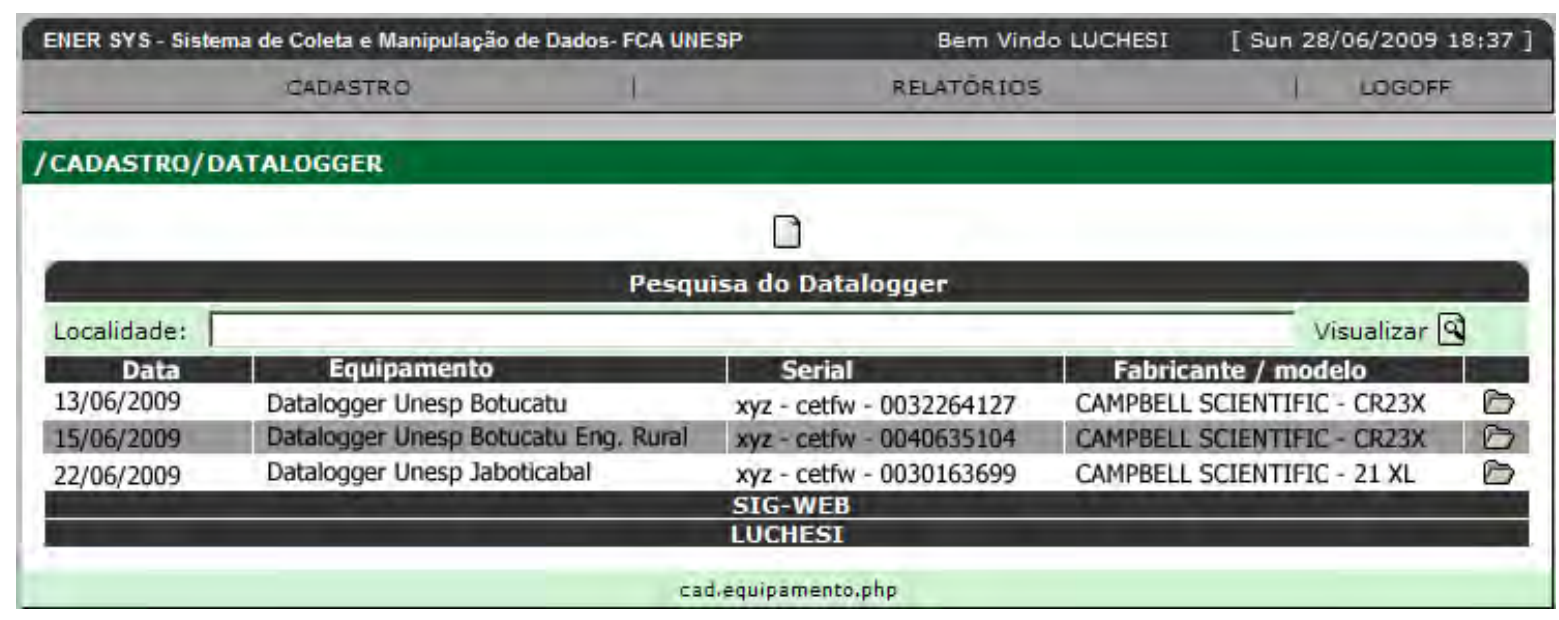

Figura 13 - Pesquisa de equipamentos cadastrados.

A efetiva inclusão dos dados do equipamento se dá através do formulário exibido na Figura 14. Cadastrar os equipamentos representa o ato onde o usuário alimenta o programa com os dados (nome do equipamento, local, versão, ensaio) pertinentes ao sistema de aquisição automático dos dados. Tal formulário é acessado através da seleção do ícone situado em sua porção superior central.

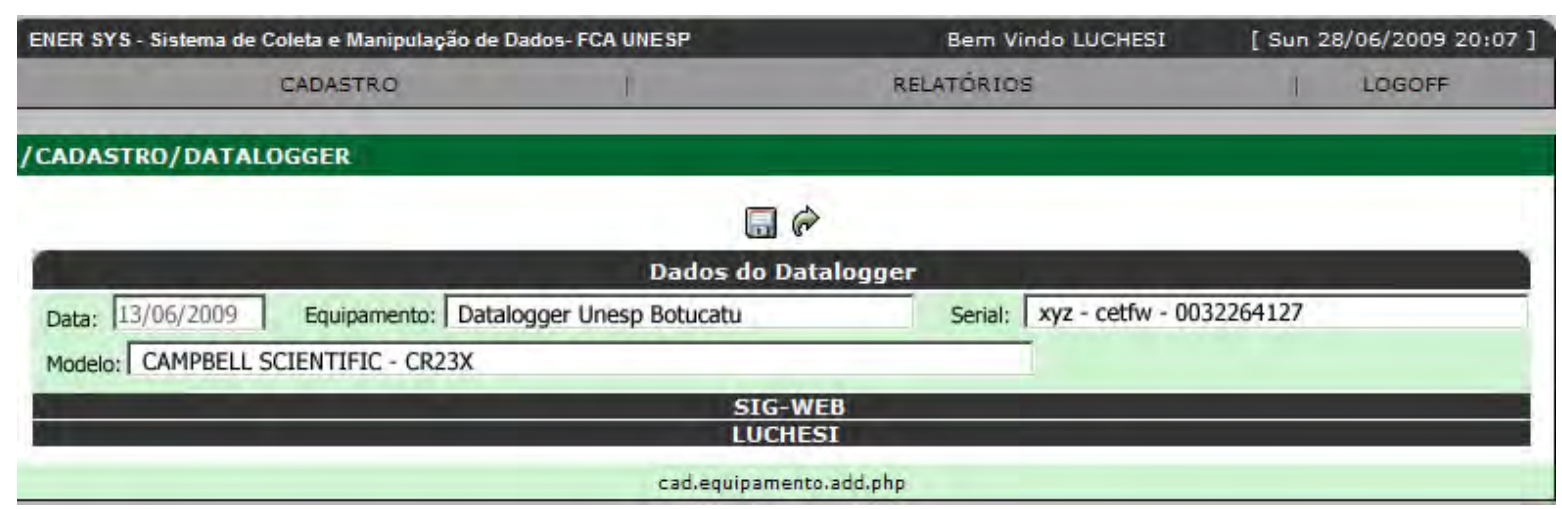

Figura 14 - Informações do equipamento de aquisição de dados. 
Uma vez selecionado certo equipamento através da pesquisa, é possível editar seus dados ou excluí-lo dos registros. A seleção do ícone de edição permite alterar os dados registrados. A seleção do ícone de exclusão - representado por uma lixeira - exclui o registro do equipamento. A Figura 15 mostra o formulário que permite tais operações.

Em todos os formulários de cadastro de equipamentos, o campo Data é carregado automaticamente com a data atual.

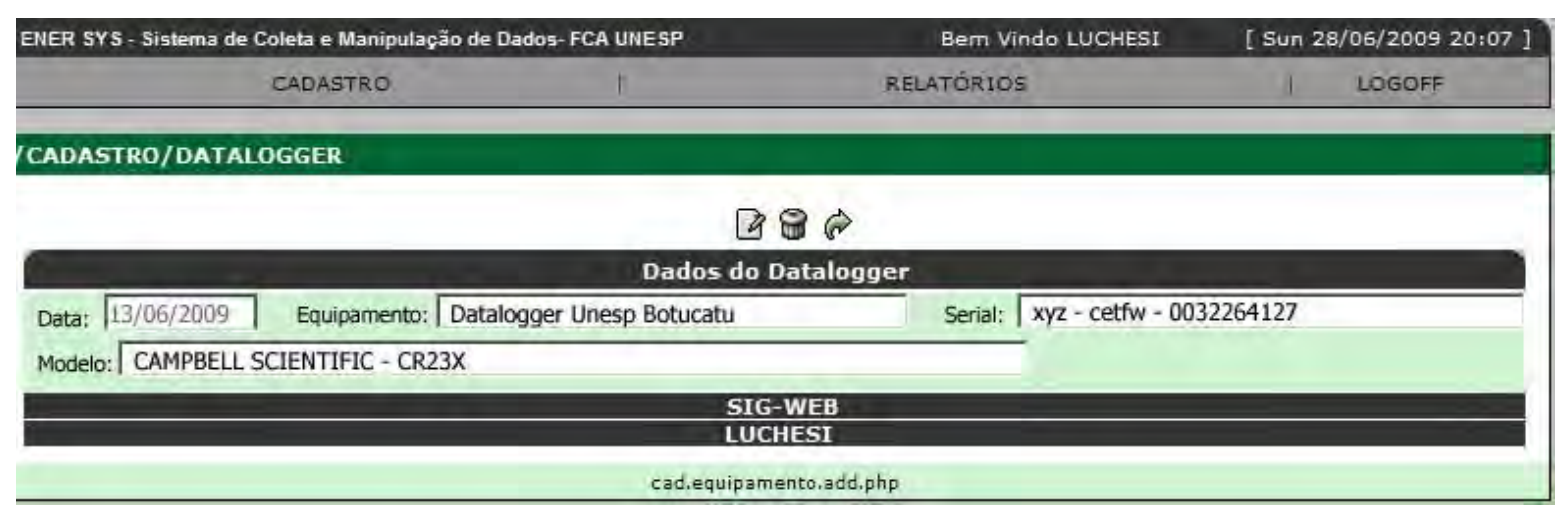

Figura 15 - Formulário de acesso à edição e exclusão de equipamentos.

Além do cadastro de equipamentos, o usuário também pode realizar operações com a opção ensaio.

A Figura 16 apresenta formulário de resultado de pesquisa de ensaios já cadastrados. A exibição deste resultado ocorre assim que o usuário acessa a opção ensaios no menu principal.

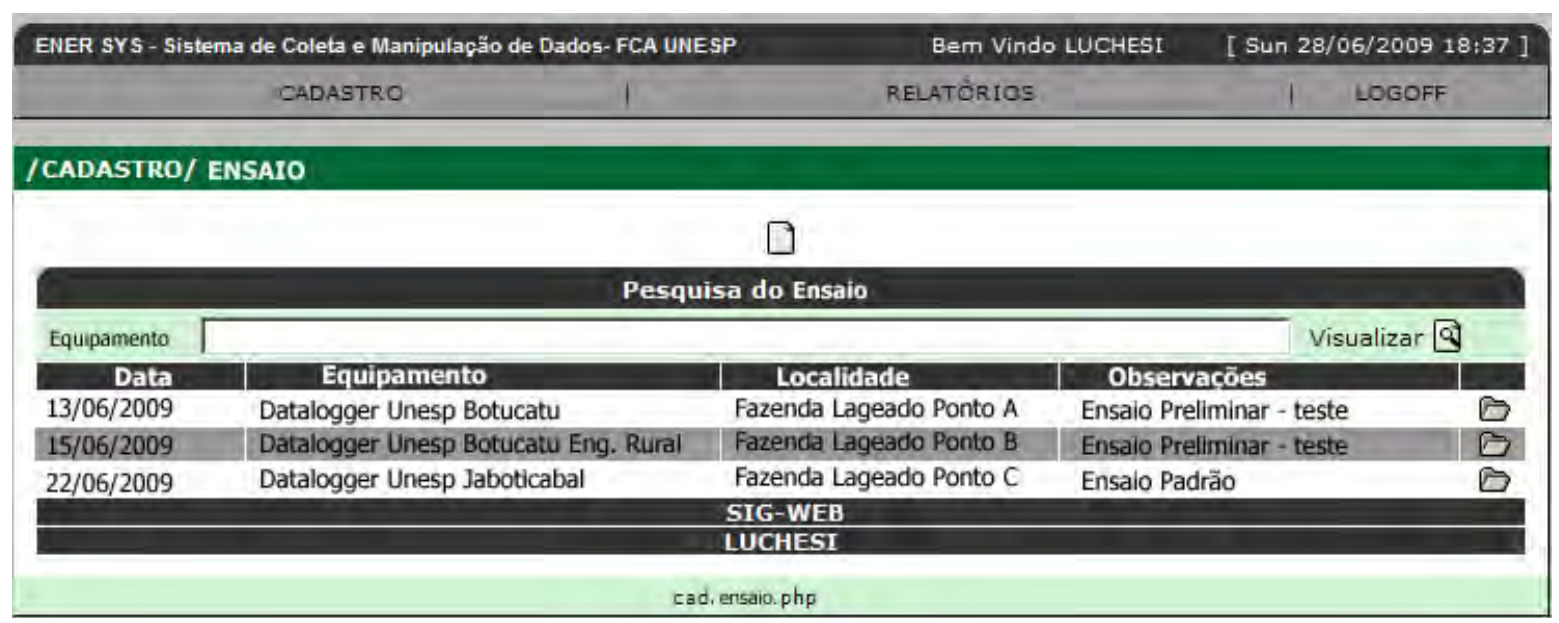

Figura 16 - Pesquisa dos ensaios. 
No formulário exibido na Figura 17, o usuário pode incluir dados de um ensaio. Caracteriza-se como ensaio os dados da amostra Vale observar que o campo Equipamento só pode ser preenchido com equipamentos previamente cadastrados.

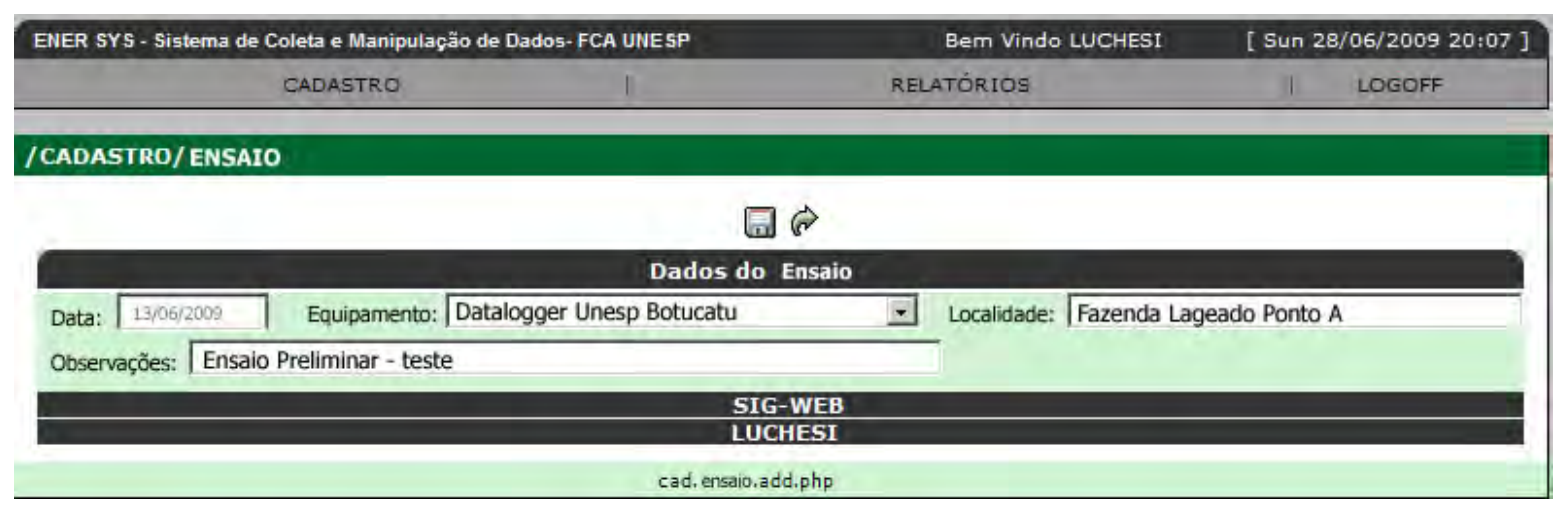

Figura 17 - Cadastro do ensaio.

Uma vez selecionado um ensaio (dados da amostragem) através da pesquisa, é possível editar seus dados ou excluí-lo dos registros. O ícone de edição permite alterar os dados registrados. O ícone de exclusão - representado por uma lixeira - exclui o registro do equipamento. A Figura 18 apresenta o formulário que permite tais operações.

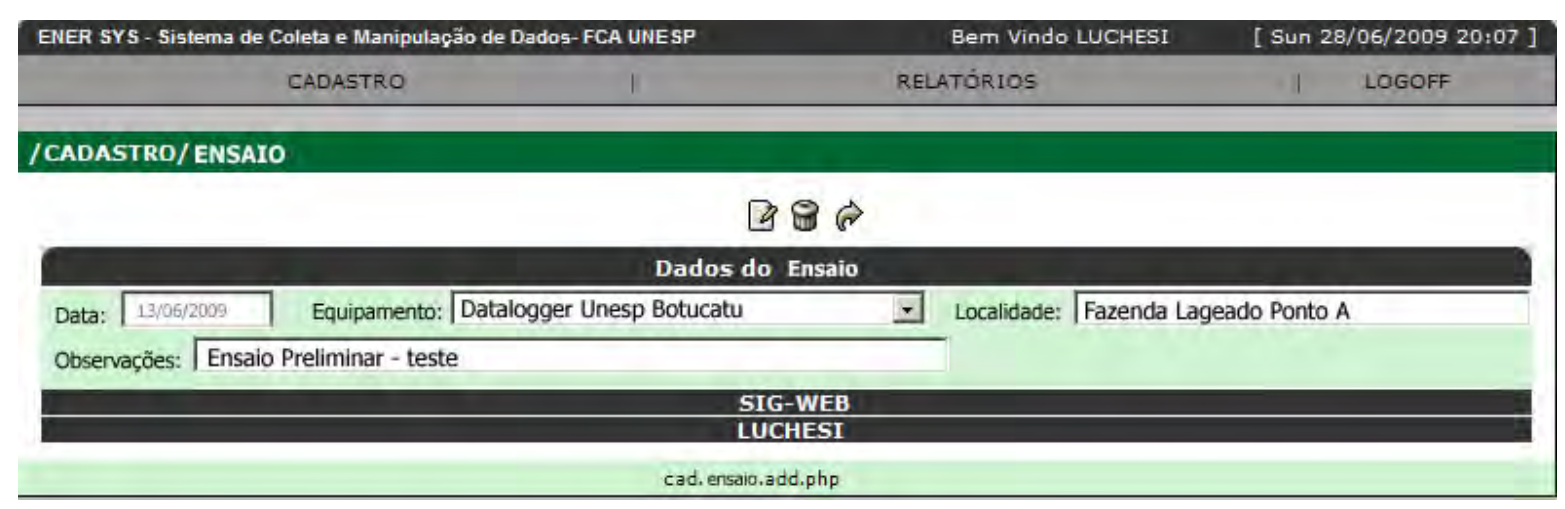

Figura 18 - Formulário de edição e exclusão do ensaio.

A edição e exclusão são acessadas através dos respectivos ícones, localizados na porção superior central da tela. 
A Figura 19 apresenta a página de importação dos dados oriundos do dispositivo de aquisição automática de dados. Importar os dados significa reunir em uma única base os dados coletados e armazenados no formato texto entre 2005 e 2008.

O formulário apresenta o nome do arquivo importado e permite sua visualização, através da seleção de ícone identificado.

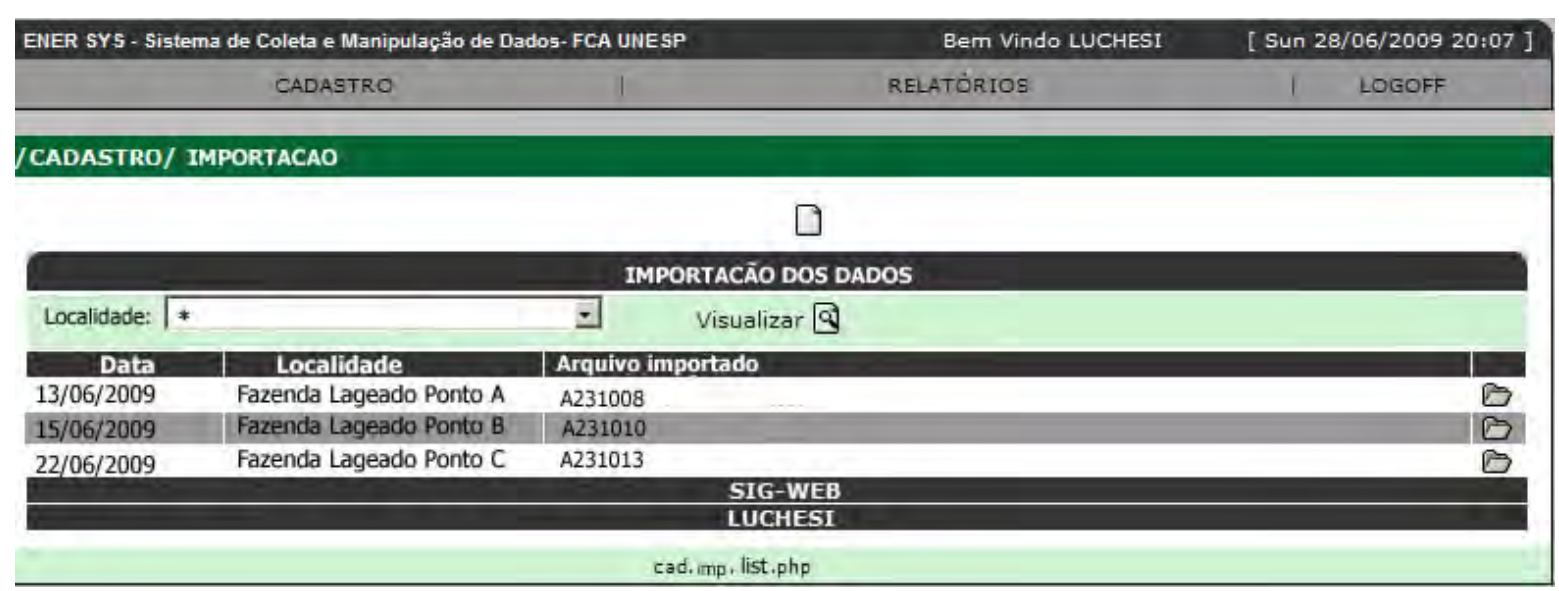

Figura 19 - Listagem dos arquivos importados.

O ícone de inclusão de arquivo para importação (porção superior central) leva o usuário ao formulário que viabiliza tal operação. A inclusão de um arquivo se dá através do carregamento do campo Arquivo, conforme mostrado na Figura 20. O campo Data deste formulário é preenchido automaticamente e o campo Localidade deve ser carregado com localidades previamente cadastradas.

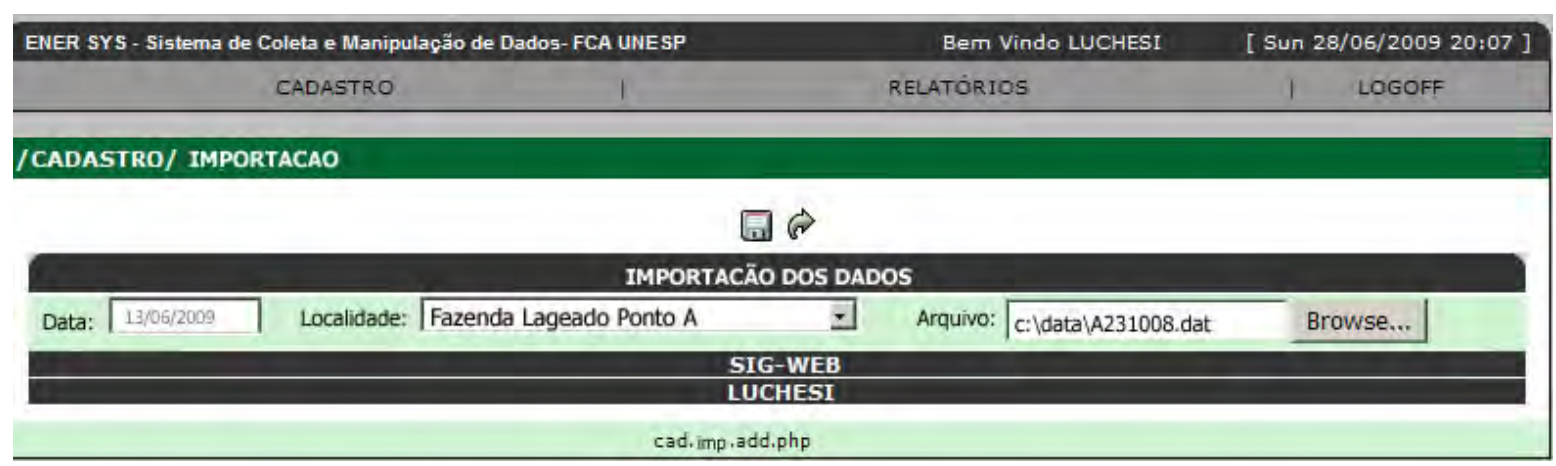

Figura 20 - Inclusão de um arquivo para importação. 
Após o cadastro do equipamento, a seleção e a importação do arquivo de dados gerado pelo sistema automático de aquisição de dados, através de um algoritmo de busca e manipulação, o sistema seleciona somente as linhas a serem manipuladas posteriormente. Neste caso, somente as linhas 100 e 110 que contém as informações importantes que serão armazenadas em um banco de dados através de comandos para uma consulta posterior.

Após a importação dos dados organizados e armazenados no período de 2005 a 2008, o usuário pode selecionar de uma forma mais simples e organizada os dados das seguintes variáveis: temperatura, umidade, velocidade dos ventos, direção dos ventos, precipitação e irradiância.

É possível visualizar e avaliar os dados coletados pelo dispositivo de aquisição automática de dados por meio do formulário apresentado na Figura 21.

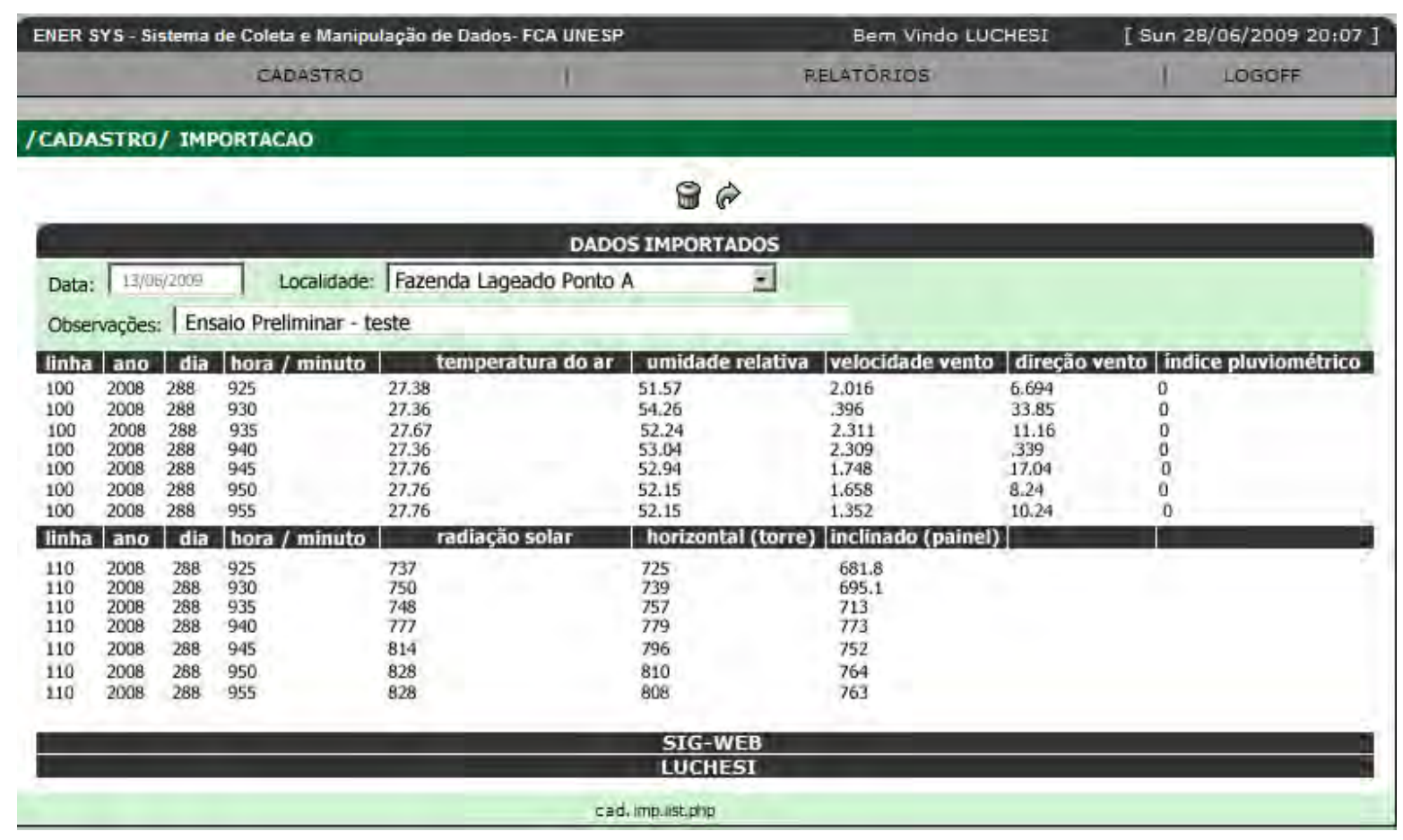

Figura 21 - Visualização dos dados importados.

Através dos relatórios gerados pelo sistema, é possível visualizar as informações processadas através de um sistema de aquisição automático de dados para apoiar o processo de tomada de decisão, de uma forma mais simples ao usuário final. A Figura 22 
apresenta o formulário por meio do qual o usuário escolhe a localidade, os períodos inicial e final das coletas e as variáveis de estudo.

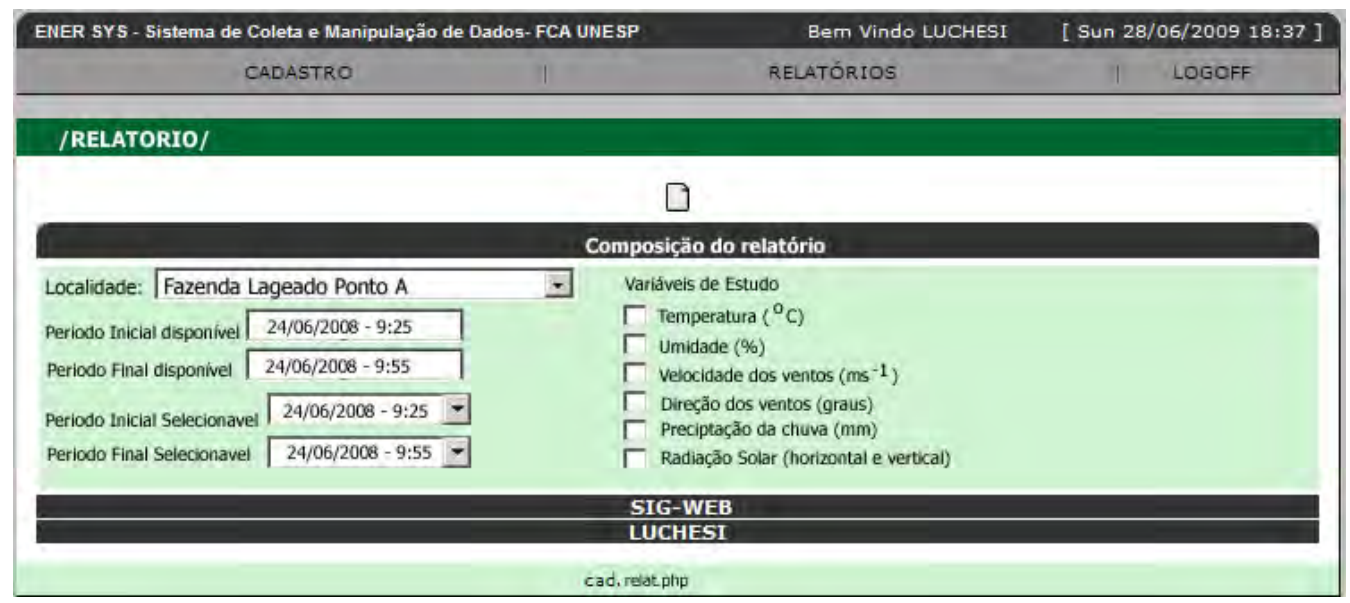

Figura 22 - Formulário de escolha dos dados do relatório.

A última etapa do processo de desenvolvimento consiste na análise das informações disponibilizadas pelas tecnologias empregadas, através dos relatórios gerados, a serem utilizados no processo de tomada de decisão no setor de agroenergia.

A análise consiste na organização dos dados das seguintes variáveis: temperatura, umidade, velocidade dos ventos $\left(\mathrm{m} . \mathrm{s}^{-1}\right)$, direção dos ventos (graus), chuva (mm) e irradiância (horizontal e vertical), armazenados no período de 2005 a 2008 e obtidos através da aquisição automática dos dados baseando-se em fórmulas estatísticas. 
A Figura 23 apresenta relatório analítico gerado pelo Ener Sys.

\begin{tabular}{|c|c|c|c|c|c|c|c|c|}
\hline \multicolumn{9}{|c|}{ Medidas de Posicão } \\
\hline & Radiação & $\begin{array}{c}\text { Temperatu } \\
\text { ra do ar }\end{array}$ & $\begin{array}{l}\text { Umidade } \\
\text { Relativa }\end{array}$ & $\begin{array}{c}\text { Velocidade } \\
\text { do Vento }\end{array}$ & $\begin{array}{c}\text { Direção do } \\
\text { vento }\end{array}$ & $\begin{array}{c}\text { Indice } \\
\text { Pluviométri } \\
\text { co }\end{array}$ & $\begin{array}{c}\text { Horizontal } \\
\text { (torre) }\end{array}$ & $\begin{array}{c}\text { Inclinado } \\
\text { (painel) }\end{array}$ \\
\hline Moda & 828,00 & 27,76 & 52,15 & & & 0,00 & & \\
\hline Mediana & 777,00 & 27,67 & 52,24 & 1,75 & 10,24 & 0,00 & 779,00 & 752,00 \\
\hline $\begin{array}{c}\text { Media } \\
\text { Aritmética }\end{array}$ & 783,14 & 27,58 & 52,62 & 1,68 & 12,51 & 0,00 & 773,43 & 734,56 \\
\hline Valor (MAX) & 828,00 & 27,76 & 54,26 & 2,31 & 33,85 & 0,00 & 810,00 & 773,00 \\
\hline Valor (MIV) & 737,00 & 27,36 & 51,57 & 0,40 & 0,34 & 0,00 & 725,00 & 681,80 \\
\hline Amplitude & 91,00 & 00,40 & 2,69 & 1,91 & 33,51 & 0,00 & 085,00 & 91,20 \\
\hline \multicolumn{9}{|c|}{ Medidas de Dispenão } \\
\hline Variância & 1579,48 & 0,04 & 0,78 & 0,44 & 113,85 & 0,00 & 1145,62 & 1377,15 \\
\hline Desvio Padrão & 39,74 & 0,20 & 0,88 & 0,67 & 10,67 & 0,00 & 33,85 & 37,11 \\
\hline $\begin{array}{l}\text { Coeficiente de } \\
\text { Variação }\end{array}$ & 19,71 & 137,30 & 59,73 & 2,53 & 1,17 & & 22,85 & 19,79 \\
\hline Contagem & 7 & 7 & 7 & 7 & 7 & 7 & 7 & 7 \\
\hline
\end{tabular}

Figura 23 - Relatório analítico do Ener Sys.

O Ener Sys é capaz de fornecer gráficos que comparam as variáveis obtidas em relação ao tempo. 
A Figura 24 apresenta as variações da irradiância (watts.m ${ }^{-2}$.

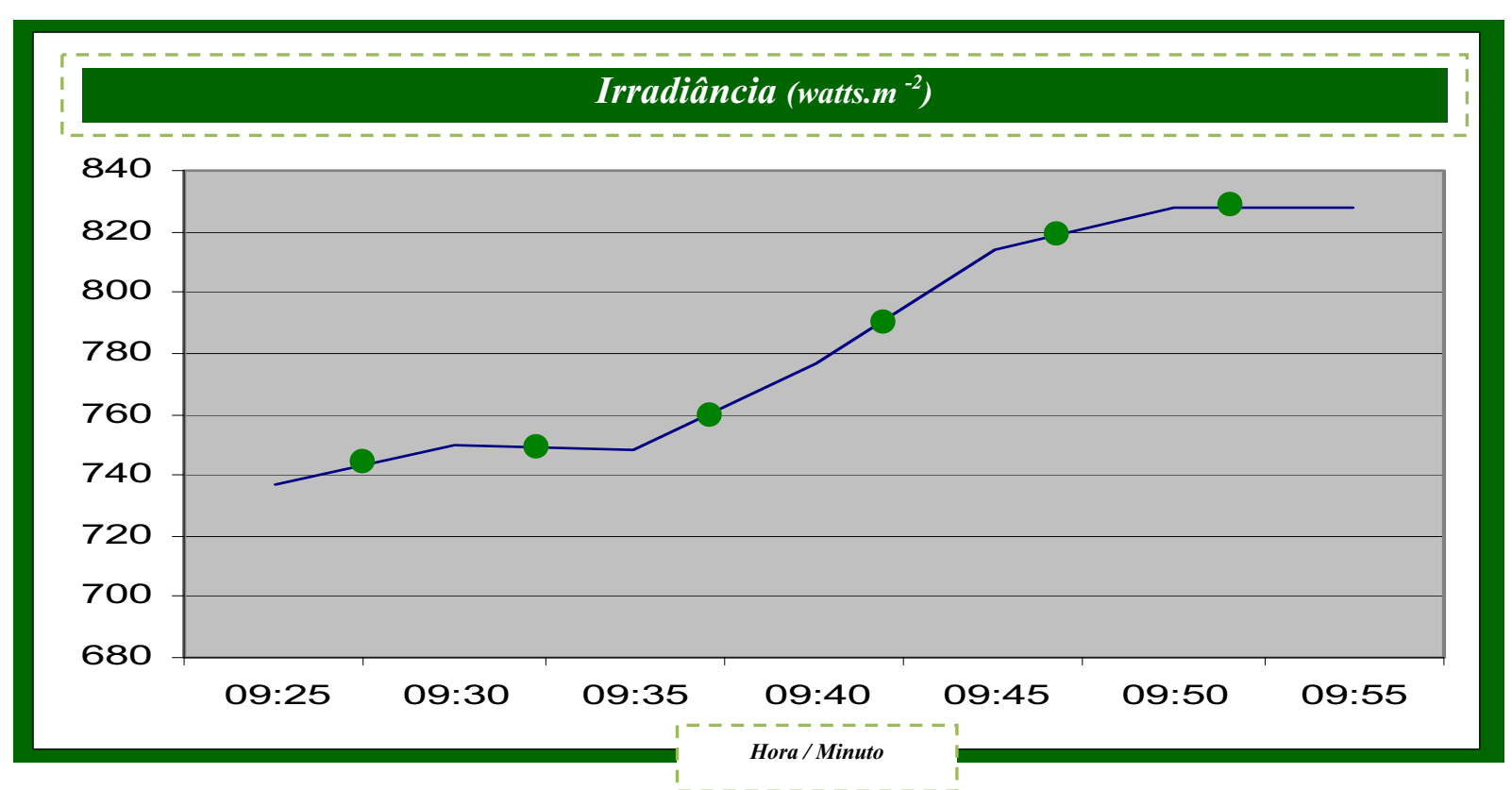

Figura 24 - Variações da irradiância.

A Figura 25 mostra as variações de temperatura $\left({ }^{\circ} \mathrm{C}\right)$.

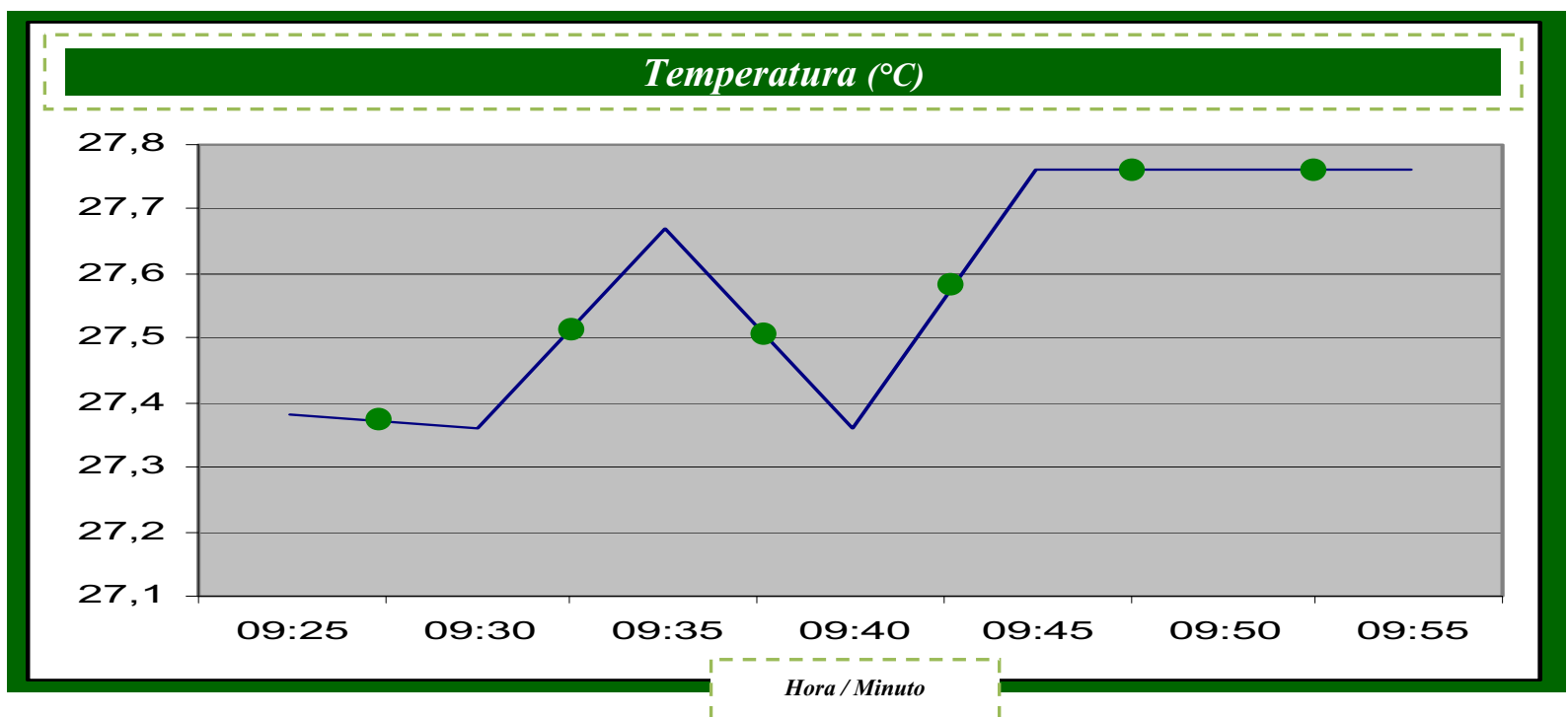

Figura 25 - Variações da temperatura. 
A Figura 26 apresenta as variações de umidade relativa do ar (\%).

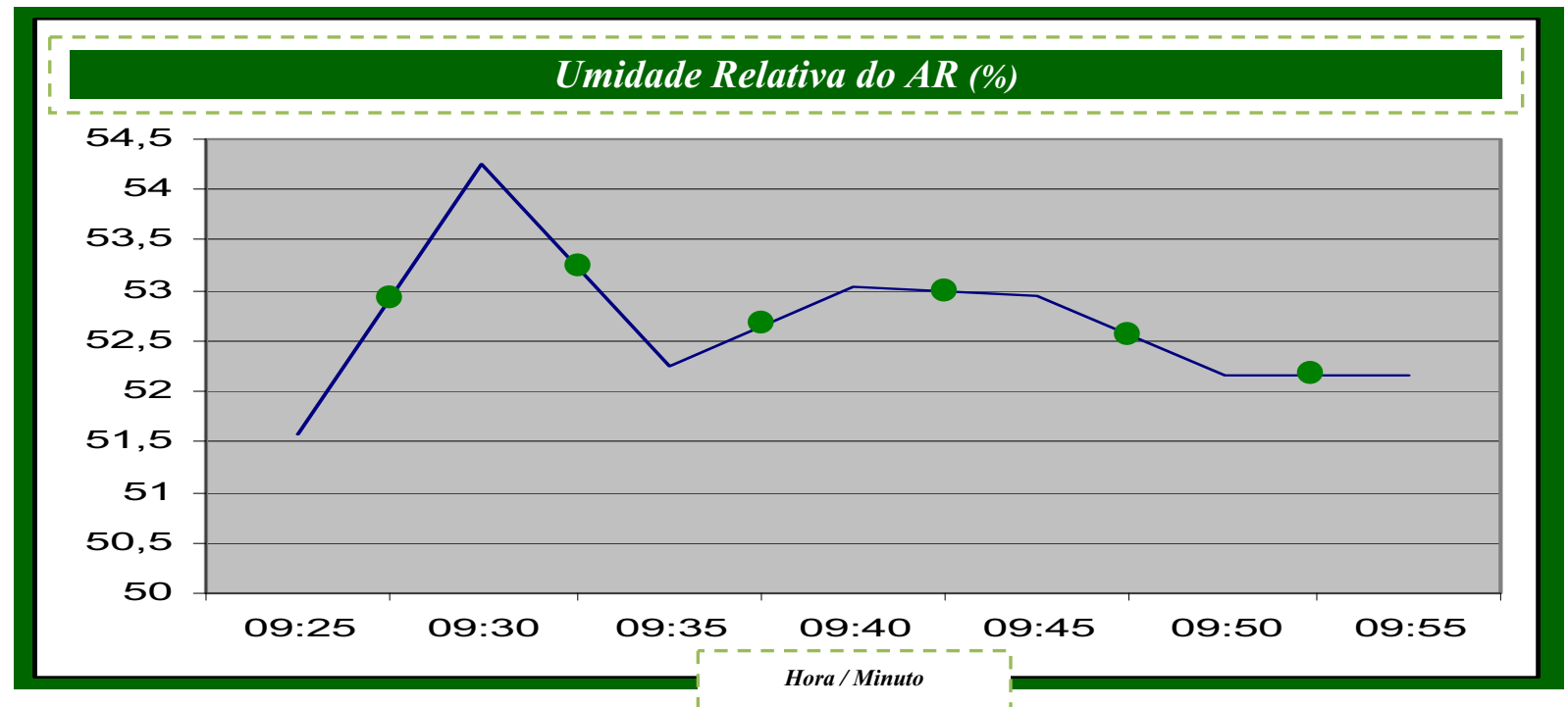

Figura 26 - Variações da umidade relativa.

A Figura 27 apresenta as variações da velocidade do vento $\left(\mathrm{m} \cdot \mathrm{s}^{-1}\right)$.

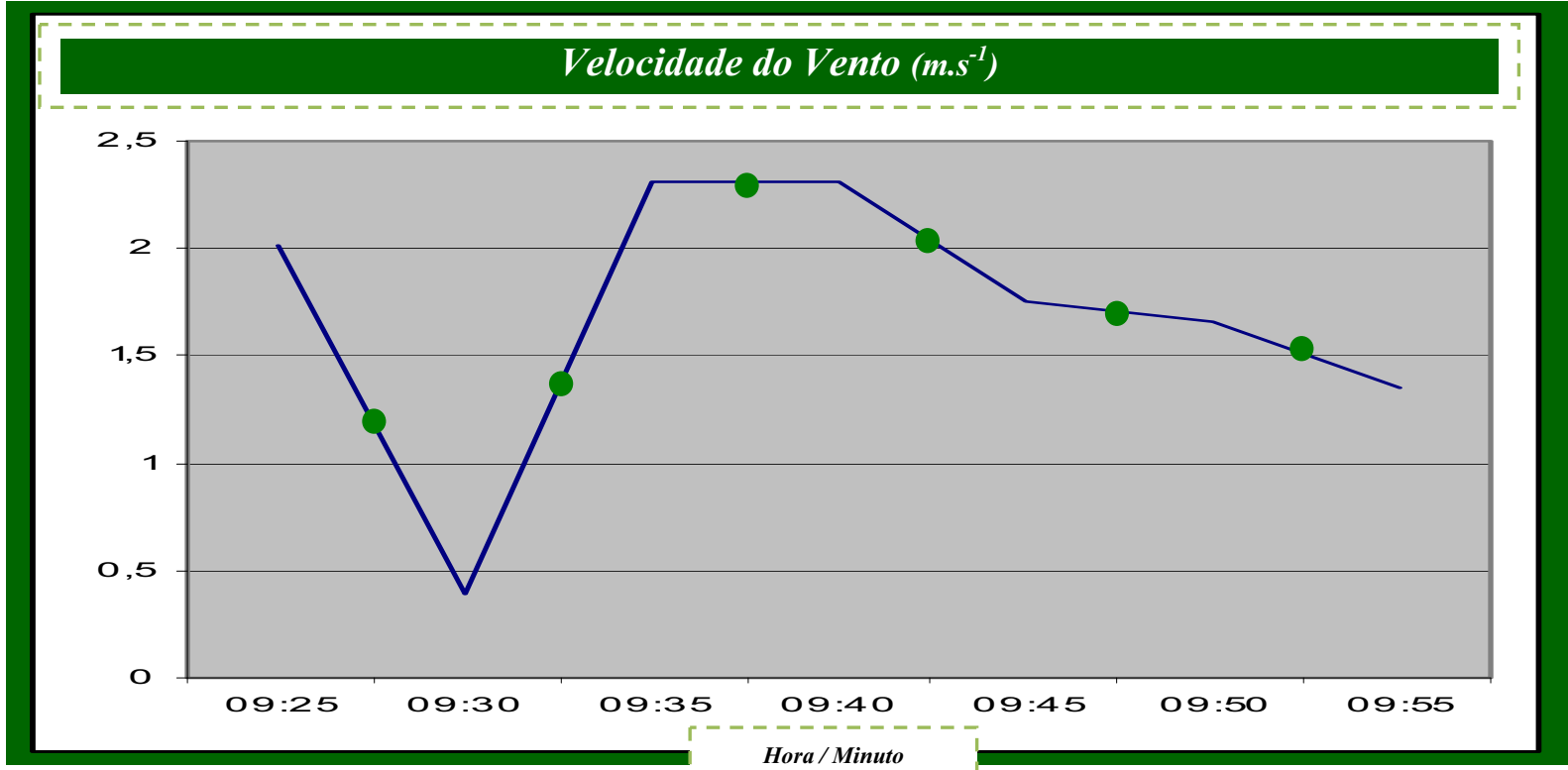

Figura 27 - Variações da velocidade do vento. 
A Figura 28 mostra as variações da direção do vento ( ${ }^{\circ}$ Graus).

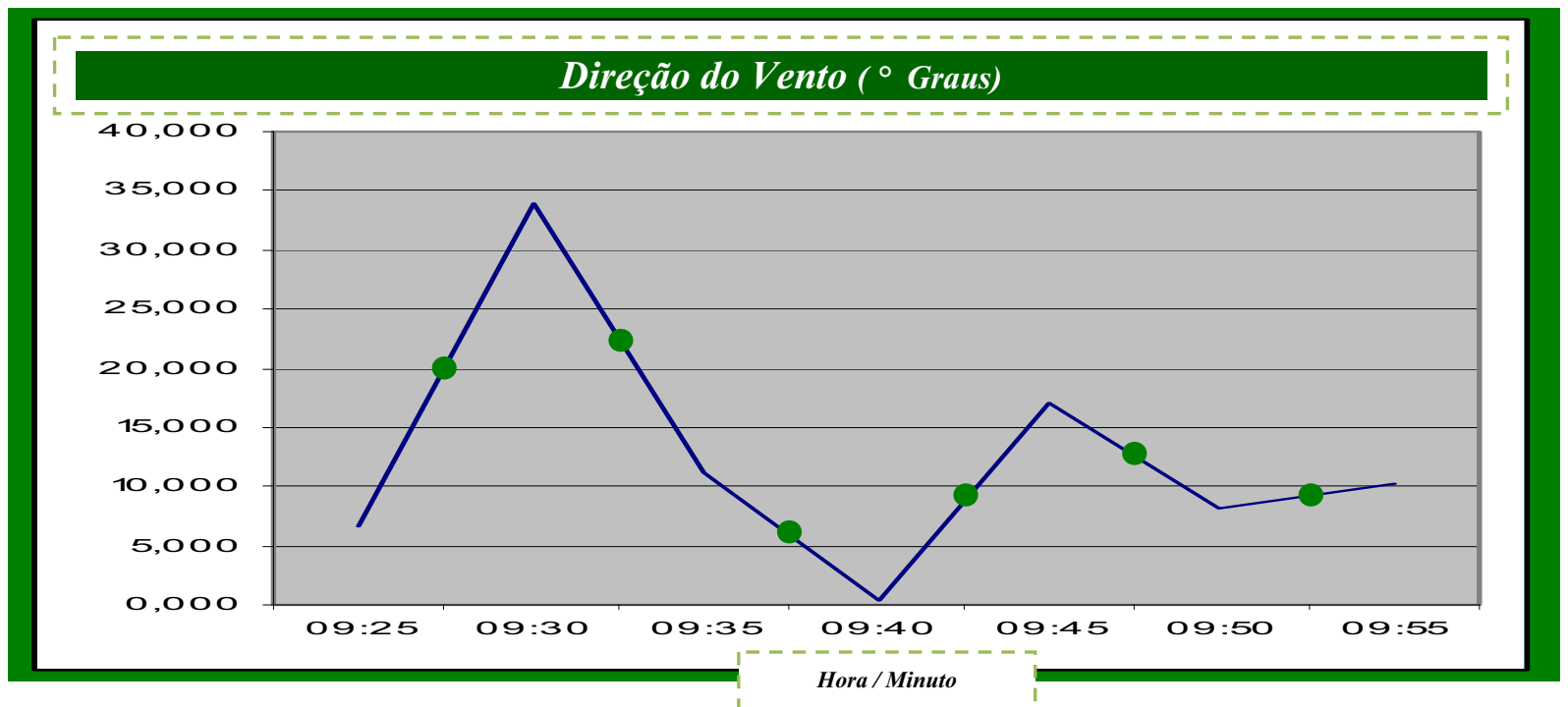

Figura 28 - Variações da direção do vento.

A Figura 29 apresenta as variações do índice pluviométrico (mm).

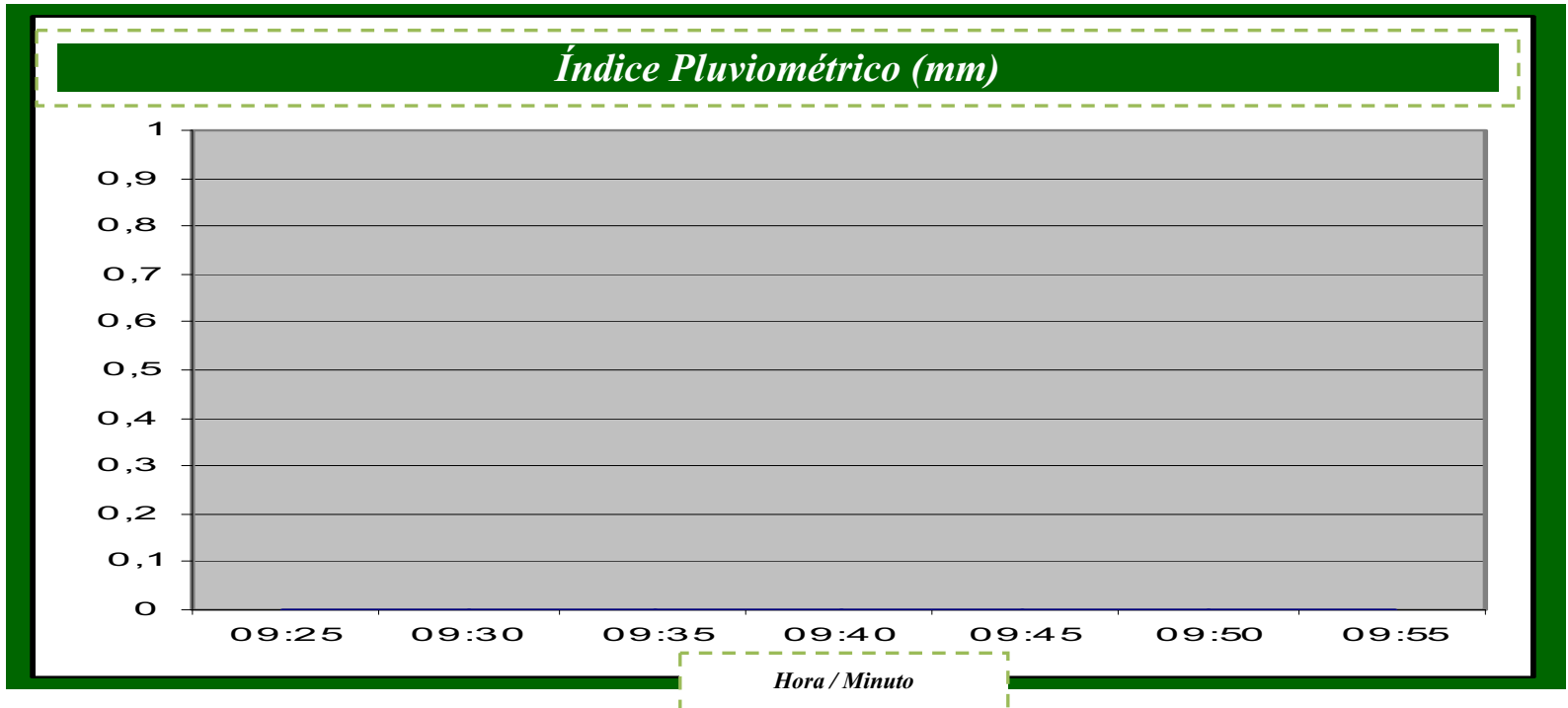

Figura 29 - Variações do índice pluviométrico. 
A Figura 30 apresenta a variação da irradiância horizontal - torre (watts.m ${ }^{-2}$.

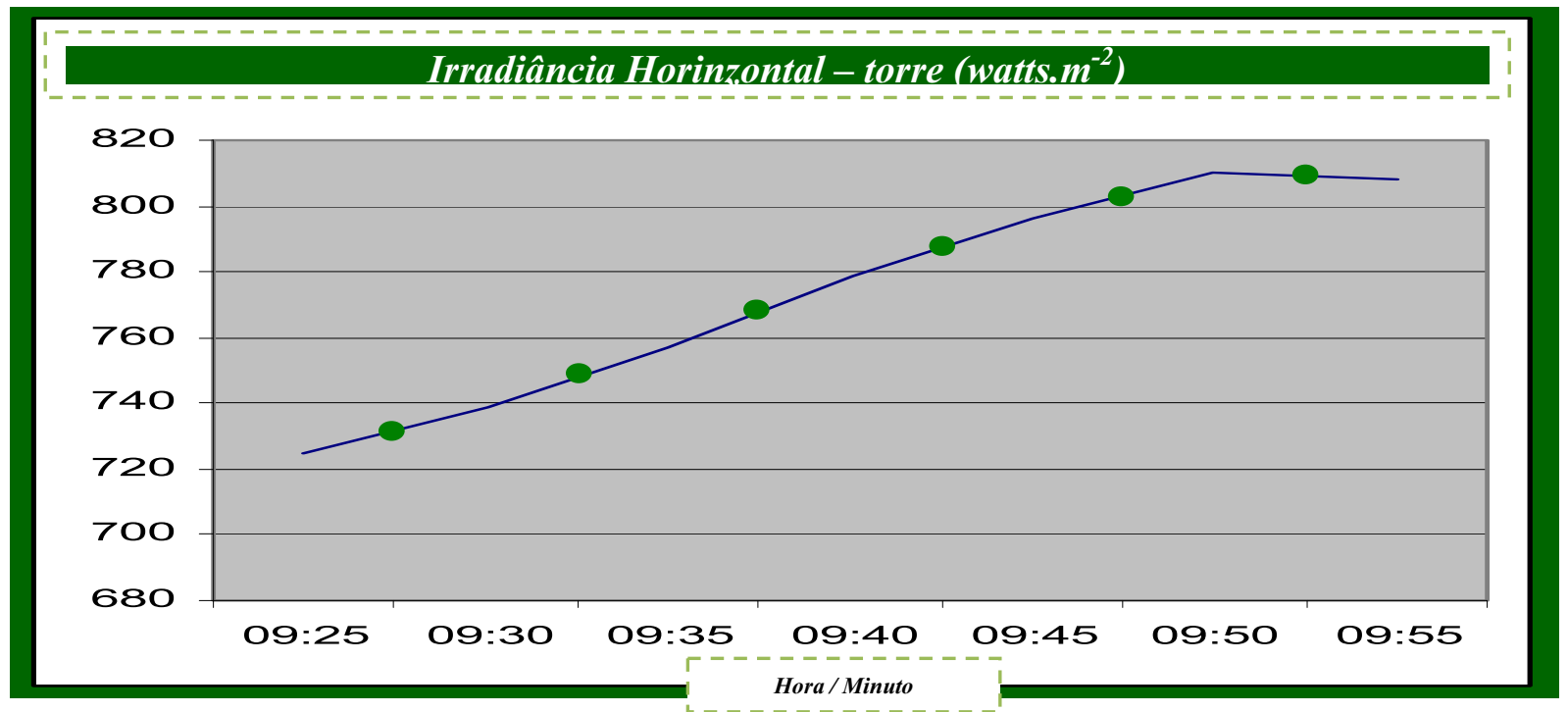

Figura 30 - Variações da inclinação.

A Figura 31 apresenta a variação da irradiância inclinado - painel(watts.m ${ }^{-2}$.

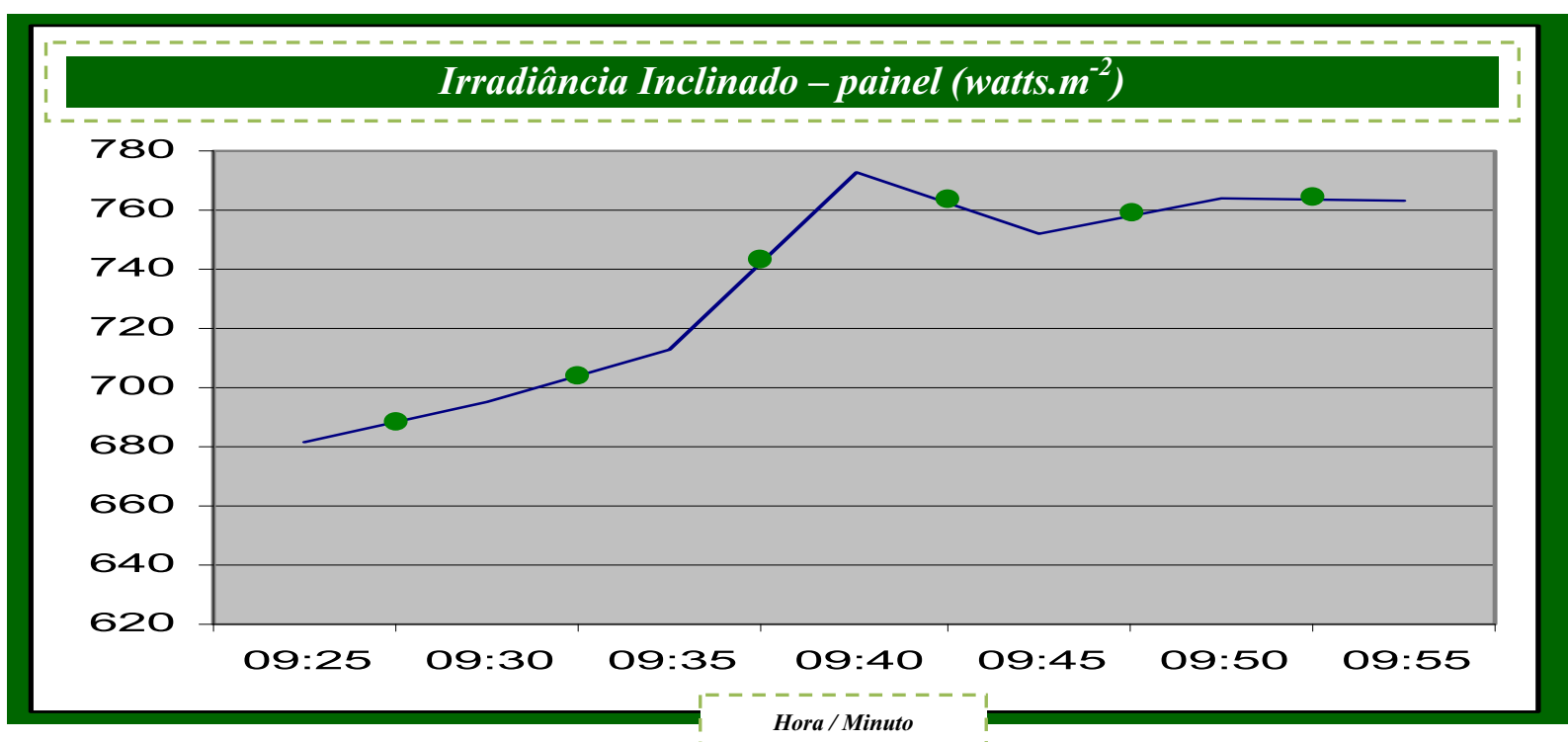

Figura 31 - Variações do painel. 


\section{CONCLUSÕES}

O objetivo proposto no presente trabalho foi atendido com o desenvolvimento do programa computacional EnerSys que reuniu, em um banco de dados unificada, os dados coletados através de um sistema eletrônico de aquisição de dados.

Os resultados obtidos apontam que a abordagem desta pesquisa facilitou o acesso a informações armazenadas em grandes massas de dados.

Diante da quantidade de variáveis analisadas neste tipo de estudo, criou-se uma base de dados estruturada para organizar os dados armazenados no período de 2005 a 2008.

Ao término da pesquisa, foi possível constatar que o programa desenvolvido facilitou o processamento dos dados e proporcionou ganhos na visualização das informações como temperatura $\left({ }^{\circ} \mathrm{C}\right)$, umidade $(\%)$, velocidade dos ventos $\left(\mathrm{m} \cdot \mathrm{s}^{-1}\right)$, direção dos ventos (graus), chuva (mm) e irradiância (horizontal e vertical). 


\section{REFERÊNCIAS BIBLIOGRÁFICAS}

AJIMASTRO JR., C.; PAZ, M. E. Identificação eletrônica. In: CONGRESSO BRASILEIRO DE ZEBUÍNOS, 3., 1998, Uberaba, MG. A integração da cadeia produtiva: anais... Uberaba: ABCZ, 1998. p. 167-169.

ALMEIDA, H. A.; SOUZA, J. A.; ALCÂNTARA, H. M. Análise comparativa de dados meteorológicos obtidos por estação convencional e automática no semi-árido paraibano. Revista Brasileira de Agrometeorologia, Santa Maria, RS, v. 16, n. 1, p. 58-66, abr. 2008.

ALVES, W. P. Delphi 2005: aplicações de banco de dados com InterBase 7.5 e MySQL 4.0.23. São Paulo: Érica, 2005. 544p.

AYOADE, J. O. Introdução à climatologia para os trópicos. São Paulo: DIFEL, 1986. $332 \mathrm{p}$.

BARBOSA, M. P.; LOPES, M. A.; ZAMBALDE, A. L. Programa computacional para gerenciamento de rebanhos bovinos: desenvolvimento e avaliação pela softhouse. Revista Brasileira de Agroinformática, Viçosa, MG, v. 3, n. 1, p. 14, 2000.

BRAGA, N. C. Aquisição de dados. São Paulo: Saber Eletrônica, 2008. Disponível em: $<$ http://www.sabereletronica.com.br/secoes/leitura/831>. Acesso em: 2 fev. 2009.

BURRELL, J.; BROOKE, T.; BECKWITH, R. Vineyard computing: sensor networks in agricultural production. Pervasive Computing, Hillsboro, OR, USA, v. 3, n. 1, p. 38-45, Jan./Mar. 2004. 
CAMPOS FILHO, M. P. Os sistemas de informação e as modernas tendências da tecnologia e dos negócios. Revista de Administração de Empresas, São Paulo, v. 34, n. 6, p. 33-45, nov./dez. 1994.

CAMPOS, F. H. Desenvolvimento de um programa computacional destinado à unidade móvel de ensaio na barra de tração (UMEB) para a avaliação do desempenho de tratores. 2009. 81 f. Dissertação (Mestrado em Energia na Agricultura)-Faculdade de Ciências Agronômicas, Universidade Estadual Paulista, Botucatu, 2009.

CANTU, C. H. Firebird essencial. São Paulo: Ciência Moderna, 2005. 332p.

CASTRO NETO, M.; SILVA, L. M.; PINTO, P. A. Designing Internet dynamic presences in low tech rural environments: a case study. In: WORLD CONGRESS ON COMPUTERS IN AGRICULTURE AND NATURAL RESOURCES, 2002, Foz do Iguaçu. Anais... Foz do Iguaçu: ASAE, 2002. p. 697-703.

CUNHA, A. R. Parâmetros agrometeorológicos de cultura de pimentão (Capiscum annuum L.) em ambientes protegido e campo. 2001. $128 \mathrm{f}$. Tese (Doutorado em Agronomia/Energia na Agricultura)-Faculdade de Cicências Agronômicas, Universidade Estadual Paulista, Botucatu, 2001.

DATE, C. J. Introdução a sistemas de bancos de dados. Rio de Janeiro: Campus, 2000. 803 p.

ELMASRI, R.; NAVATHE, S. B. Sistemas de banco de dados. São Paulo: Pearson Education, 2005. 724 p.

FIGUEIRA, A. S.; ZAMBALDE, A. L. Estrutura de tecnologia da informação adotada por produtores e cooperativas da cadeia produtiva do leite. Revista Brasileira de Agroinformática, Viçosa, MG, v. 5, p. 1-12, 2003.

FREITAS, H. Elementos contributivos à integração da tecnologia da informação na gestão de fazendas agropecuárias. In: SALÃO DE INICIAÇÃO CIENTÍFICA, 8., 2006, Porto Alegre. Ciências sociais aplicadas: sessão 9... Porto Alegre: PPGA/UFRGS, 2006. p. 283. 
GARCIA, R. F. et al. Programa computacional para aquisição de dados para avaliação de máquinas agrícolas. Revista Brasileira de Engenharia Agrícola e Ambiental, Campina Grande, PB, v. 7, n. 2, p. 375-381, 2003.

GUERRA, S. P. S. Desenvolvimento de um sistema informatizado de menor custo para aquisição e armazenagem de dados de sesores analógicos e receptor GPS. 2006. $118 \mathrm{f}$. Dissertação (Mestrado em Energia na Agricultura)-Faculdade de Ciências Agronômicas, Universidade Estadual Paulista, Botucatu, 2006.

JESUS, J. C. S.; ZAMBALDE, A. L.; SEGRE, L. M. Considerações estratégicas sobre o processo de informatização das empresas/propriedades rurais. In: FEIRA E CONGRESSO DE INFORMÁTICA APLICADA À AGROPECUÁRIA E AGROINDÚSTRIA, 1995, Juiz de Fora. Trabalhos apresentados... Juiz de Fora: Agrosoft, 1995. Disponível em: $<$ http://www.agrosoft.org.br/trabalhos/ag95/doc30.htm>. Acesso em: 2 fev. 2009.

JOHNSON, G. W. LabVIEW graphical programming: practical applications in instrumentation and control. New York: McGraw-Hill. 1997. 665 p.

LAUDON, K. C.; LAUDON, J. P. Information systems and the internet: a problem solving approach. 2nd ed. Rio de Janeiro: LTC, 1999. 389 p.

LAUNAY, M.; GUERIF, M. Assimilating remote sensing data into a crop model to improve predictive performance for spatial applications. Agriculture, Ecosystems e Environment, Avignon, França, v. 111, n. 1-4, p. 321-339, Dec. 2005.

LOPES, M. A. Informática aplicada à bovinocultura. Jaboticabal: FUNEP, 1997. 82 p.

MACHADO, F.; ABREU, M. Projeto de banco de dados. 6. ed. São Paulo: Érica, 2002.

MACHADO, J. G. C. F.; NANTES, J. F. D.; ROCHA, E. C. O processo de informatização das propriedades rurais: um estudo de multicaso na pecuária de corte. Revista Brasileira de Agroinformática, Viçosa, MG, v. 4, n. 1, p. 28-46, 2002.

MARCON, A. M. Aplicações de banco de dados para internet. 2. ed. São Paulo: Érica, 2002. 366p. 
MEIRA, C. A. A. et al. Agroinformática: qualidade e produtividade na agricultura. Caderno de Ciência e Tecnologia, Brasília, DF, v. 13, n. 2, p. 175-194, 1996.

MEIRELLES, F. S. Informática: novas aplicações com microcomputadores. 2. ed. São Paulo: Pearson Educacional, 1994. 615 p.

MENDONÇA, F. C. Evolução da Informática na agropecuária brasileira e suas tendências. 1995. 65 p. Monografia (Graduação em Engenharia Agronômica - Universidade Federal de São Carlos, 1995.

MOHAMMED, A. R.; TARPLEY, L. High nighttime temperatures affect rice productivity through altered pollen germination and spikelet fertility. Agricultural and Forest Meteorology, Beaumont, TX, v. 149, n. 6-7, p. 999-1008, June 2009.

MOZNY, M. et al. The impact of climate change on the yield and quality of Saaz hops in the Czech Republic. Agricultural and Forest Meteorology, Komorany, v. 149, n. 6-7, p. 913919, June 2009.

NIEDERAUER, J. Desenvolvendo websites com PHP. São Paulo: Novatec, 2008. 272p.

NORTON, P. Peter Norton's introduction to computers. São Paulo: Makron Books, 1996. $619 \mathrm{p}$.

O'BRIEN, K. A. Sistemas de informação e as decisões gerenciais na era da Internet. 2. ed. São Paulo: Saraiva, 2004. 526p.

OLIVEIRA, D. P. R. Sistemas de informações gerenciais: estratégicas, táticas, operacionais. 8. ed. São Paulo: Atlas, 2002. 288 p.

PEREIRA, A. R.; ANGELOCCI, L. R., SENTELHAS, P. C. Agrometeorologia: fundamentos e aplicações práticas. Guaíba: Agropecuária, 2002. 478 p.

SARAIVA, A. M.; MASSOLA, A. M. A.; CUGNASCA, C. E. An object model for field information systems. In: INTERNATIONAL CONFERENCE ON PRECISION 
AGRICULTURE, 4., 1998, Saint Paul. Proceedings... Saint Paul, MN, EUA: ASA; CSSA; SSSA, 1998. p. 1355-1366.

SEBESTA, R. W. Conceitos de linguagens de programação. 5. ed. Porto Alegre: Bookman, 2003. $638 \mathrm{p}$.

SILBERSCHAT, A.; KORTH, H. F. Sistemas de banco de dados. 3. ed. São Paulo: Makron Books, 1999. 808p.

SILVEIRA, G. M. et al. Sistema de aquisição automática para o gerenciamento de operações mecanizadas. Bragantia, Campinas, v. 64, n. 2, p. 305-310, 2005.

SIQUEIRA, J. A. C. Desempenho de um sistema híbrido eólico-fotovoltaico de pequeno porte para energização rural. 2005. 176 f. Tese (Doutorado em Agronomia/Energia na Agricultura)-Faculdade de Ciências Agronômicas, Universidade Estadual Paulista, Botucatu, 2005.

SOARES, W. PHP5: conceitos, programação e integração com banco de dados. 4. ed. São Paulo: Érica, 2007. 528p.

SOARES, W. Programando em PHP: conceitos e aplicações. 2. ed. São Paulo: Érica, 2002.

SOUKI, G. Q.; ZAMBALDE, A. L. Vantagens e limitações da informática na agropecuária. In: FEIRA E CONGRESSO DE INFORMÁTICA APLICADA À AGROPECUÁRIA E AGROINDÚSTRIA, 1999, Campinas. Trabalhos apresentados... Juiz de Fora: Agrosoft, 1999. Disponível em: <http://agrosoft.com/trabalhos/ag99/artigo59.htm>. Acesso em: 20 set. 2008.

STAIR, R. M. Princípios de sistemas de informação. 4. ed. Rio de Janeiro: LTC, 2002. $672 \mathrm{p}$.

STEPHENSON, R.; ANDERSON, P. S. Disasters and the information technology revolution. Disasters, Oxford, v. 21, n. 4, p. 305-34, 1997.

SUGIMOTO, L. O avanço brasileiro na agrometeorologia. Juiz de Fora: Agrosoft, 2005. Disponível em: $<\underline{w w w . a g r o s o f t . o r g . b r / a g r o p a g / 16893 . h t m>. ~ A c e s s o ~ e m: ~} 2$ jul. 2009. 
TSVI, K. et al. Optimization of copper treatments in organic viticulture by using a web-based decision support system. Computers and Electronics in Agriculture, Amsterdam, v. 68, n. , p. 36-43, Aug. 2009.

TUNG, N. H. Planejamento e controle financeiro das empresas agropecuárias. São Paulo: Edições Universidade-Empresa, 1992. 382 p.

VELLOSO, F. C. Informática conceitos básicos. Rio de Janeiro: Campus, 2003. 369 p.

WELLING, L.; THOMPSON, L. PHP and MySQL web development. Indianápolis: Developers Library, 2003. 871 p.

ZAMBALDE, A. L.; JESUS, J. C. S.; SEGRE, L. M. Considerações estratégicas sobre o processo de informatização das empresas/propriedades rurais. In: FEIRA E CONGRESSO DE INFORMÁTICA APLICADA À AGROPECUÁRIA E AGROINDÚSTRIA, 1995, Juiz de Fora. Trabalhos apresentados... Juiz de Fora: Agrosoft, 1995. Disponível em: $<$ http://www.agrosoft.org.br/trabalhos/ag95/doc30.htm>. Acesso em: 20 set. 2008.

ZAZUETA, F. S.; VERGOT, P.; BECK III, H. Use of personal digital assistants (PDAs) in agricultural extension programs. In: ASIAN CONFERENCE FOR INFORMATION TECHNOLOGY IN AGRICULTURE, 3., 2002, Beijing. Proceedings... Gainesville, Florida: University of Florida, 2002. p. 26-28.

ZULLO JÚNIOR, J. A utilização da informática na agropecuária. In: FEIRA E CONGRESSO DE INFORMÁTICA APLICADA À AGROPECUÁRIA E AGROINDÚSTRIA, 1995, Juiz de Fora. Trabalhos apresentados... Juiz de Fora: Agrosoft, 1995. Disponível em: $<$ http://www.agrosoft.com/agroport/docs95/doc47.htm>. Acesso em: 2 fev. 2009. 